\title{
Pancreatic cancer differential methylation atlas in blood, peri-carcinomatous and diseased tissue
}

\author{
Huan Wang' ${ }^{1 \#}$ Fan Yin ${ }^{2 \#}$, Fang Yuan ${ }^{1 \#}$, Yuehua Men ${ }^{3}$, Muhong Deng ${ }^{1}$, Yang $\mathrm{Liu}^{4}$, Qingfang $\mathrm{Li}^{1}$ \\ ${ }^{1}$ Cancer Center, General Hospital of PLA, Beijing 100086, China; ${ }^{2}$ Department of Oncology, The Second Medical Centre \& National Clinical \\ Research Center of Geriatric Disease, Chinese PLA General Hospital, Beijing 100086, China; ${ }^{3}$ Department of Dermatology, Peking University \\ Third Hospital, Beijing 100191, China; ${ }^{4}$ Endocrine Department, Chinese PLA 309 Hospital, Beijing 100193, China \\ Contributions: (I) Conception and design: H Wang, Q Li; (II) Administrative support: H Wang; (III) Provision of study materials or patients: F Yuan, \\ M Deng; (IV) Collection and assembly of data: Y Men, Y Liu; (V) Data analysis and interpretation: H Wang, F Yin, Q Li; (VI) Manuscript writing: \\ All authors; (VII) Final approval of manuscript: All authors. \\ \#These authors contributed equally to this work. \\ Correspondence to: Dr. Qingfang Li. Cancer Center, General Hospital of PLA, No. 28, Fuxing Road, Beijing 100853, China. Email: liqfluck@126.com.
}

Background: Pancreatic cancer is common in elderly persons, and less than $20 \%$ of patients present with localized, potentially curable tumors.

Methods: We compared the methylated sites and genes in pericarcinous tissues compared to cancer tissue, and blood compared to pericarcinous tissues in order to harvest methylation markers for putative diagnostic and therapy monitoring purposes.

Results: Of 15,397 CpG sites detected in 7,440 genes, 5,605 (36.4\%, 5,605 of 15,397) CpG sites were hypomethylated and 5,870 (38.12\%, 5,870 of 15,397) CpG sites were hypermethylated. We then performed Gene Ontology (GO) and KEGG analysis to systematically characterize the ten significantly differentially methylated genes: PTPRN2, MAD1L1, TNXB, PRDM16, GNAS, KCNQ1, TSNARE1, HDAC4, TBCD, and DIP2C. Meanwhile, function analysis of genes with differentially methylated sites located in promoter regions of overlap group was also performed. According to previous studies, we further screened 22 pancreatic cancer related key genes. The results suggested that these key genes can influence methylation. GO and KEGG analysis indicated that these genes are involved in a wide range of functions.

Conclusions: The identification of differentially methylated genes in this study provides valuable information for liquid biopsy methylation markers in pancreatic cancer.

Keywords: Pancreatic cancer; blood; DNA methylation; CpG sites; KEGG

Submitted Oct 22, 2018. Accepted for publication Oct 11, 2019.

doi: $10.21037 /$ tcr.2019.11.26

View this article at: http://dx.doi.org/10.21037/tcr.2019.11.26

\section{Introduction}

Pancreatic cancer is more common in elderly persons than in younger persons, and less than $20 \%$ of patients present with localized, potentially curable tumors (1). The estimated incidence of pancreatic cancer in the United States was 37,700 cases, and an estimated 34,300 patients died from the disease in 2008. The overall 5-year survival rate among patients with pancreatic cancer is $<5 \%$ (2). Several environmental factors have been implicated, but evidence of a causative role exists only for tobacco use. The risk of pancreatic cancer in smokers is 2.5 to 3.6 times that in nonsmokers (3) Some studies have shown an increased incidence of pancreatic cancer among patients with a history of diabetes or chronic pancreatitis, and there is also evidence that chronic cirrhosis, a high-fat, high-cholesterol diet, and previous cholecystectomy are associated with an increased incidence $(4,5)$.

Presently, there is no valid diagnostic marker for pancreatic cancer. Carbohydrate antigen 19-9 (CA 19-9) levels are elevated in pancreatic cancer but frequently only 
in advanced disease. It can also be elevated in other cancers, chronic pancreatitis, and autoimmune diseases such as rheumatoid arthritis. Approximately $10 \%$ of the population lacks expression of Lewis antigen, which is required to produce CA 19-9. Furthermore, CA 19-9 is used in a clinical setting based on response to treatment $(6,7)$. Up to now, a combination of complex and advanced imaging modalities, such as positron emission tomography scanning, 3 -phase computed tomography scanning, endoscopic ultrasound, laparoscopic ultrasound, endoscopic retrograde cholangiopancreatography, and trans-abdominal ultrasound, are necessary for the diagnosis of pancreatic cancer. However, several of these methods are invasive and thus risk complications. Consequently, a minimally or noninvasive marker for pancreatic cancer is urgently needed.

Epigenetics is defined as the study of mitotically or meiotically heritable variations in gene function that cannot be explained by changes in DNA sequence (8). Epigenetic modifications, such as DNA promoter hypermethylation, are known to be aspects of early carcinogenesis and have shown significant potential in the development of a useful diagnostic marker $(9,10)$. Recently, attention to its role in pancreatic cancer has recently increased. DNA methylation has gained much recent interest for its role in cancer biology. Aberrant patterns of DNA methylation can be associated with carcinogenesis and affect the regulation of genome stability and gene transcription (11). Genome wide studies of $\mathrm{CpG}$ islands have uncovered thousands of loci where differential methylation can segregate pancreatic tumor tissue from normal tissue (12).

Cancer-linked global genomic hypomethylation in tumor tissue is a common characteristic in a wide variety of malignancies, ranging from solid tumors, such as breast, colon, oral, and lung cancers, to cancers of the blood $(13,14)$. In this study, in order to identify candidate liquid biopsy methylation markers in pancreatic cancer, we have employed a global methylation profiling platform to comprehensively survey a large scale of CpG sites between blood and cancer tissues versus pericarcinous tissues. We compared pericarcinous tissues $v s$. cancer tissue and blood $v s$. pericarcinous tissues in order to harvest methylation markers for diagnostic purposes. These genes could be the most likely candidate methylation markers for future liquid biopsies in pancreatic cancer.

\section{Methods}

\section{Subjects}

Six patients with pancreatic cancer ( 2 males and 4 females, mean age: $58.83 \pm 14.95$ y), without radiation, chemotherapy and immunotherapy treatment, were recruited from the Chinese General Hospital of PLA in China (Table S1). The diagnosis of pancreatic cancer was made by at least two experienced oncologists. Sample collection was carried out accorded to the following criteria: (I) the minimum diameter of tumor was greater than $2 \mathrm{~cm}$. Meanwhile, pancreatic cancer was identified by Hematoxylin and Eosin (H\&E) staining and the ratio of cancer cells in the whole cells section was over $80 \%$. (II) Tissue adjacent to cancer was collected as far as possible from the cancer tissue in order to avoid the mistake sampling. (III) Blood samples were collected before surgery. Pancreatic cancer tissue and tissue adjacent to cancer of each patient were collected and stored in liquid nitrogen immediately for DNA extraction. All specimens were subjected to autolysis for 4 to $8 \mathrm{~h}$ and then snap-frozen at $-80{ }^{\circ} \mathrm{C}$ until use in analysis. DNA was extracted from $25 \mathrm{mg}$ samples of the tissue specimens using the QIAamp DNA Mini Kit (Qiagen) according to the manufacturer's instructions. gDNA of Blood samples were extracted by FitAmp ${ }^{\mathrm{TM}}$ Plasma/ Serum DNA Isolation Kit (Epigentek, USA) according to the manufacturer's instructions. The DNA yield and purity were determined spectrophotometrically (NanoDrop ${ }^{\circledR}$ ND1000; Thermo Fisher Scientific Inc., Waltham, MA, USA) and by gel electrophoresis, respectively. DNA of sample was stored at $-20^{\circ} \mathrm{C}$ for further study. This study was approved by the Ethics Committee of Chinese General Hospital of PLA (No. S2018013-02). All patients provided signed informed consent.

\section{DNA methylation methods}

Bisulfite conversion of $500 \mathrm{ng}$ genomic DNA was performed using the EZ DNA methylation kit (Zymo Research). DNA methylation level was assessed according to the manufacturer's instructions using InfiniumHumanMethylation450 Beadchips (Illumina Inc.). The technical schemes, the accuracy, and the high reproducibility of this array have been described previously (15). Quantitative measurements of DNA methylation were determined for 485,577 CpG dinucleotides, which covered 99\% of the RefSeq genes and were distributed across the whole gene regions, including promoter, gene body, and 30-untranslated regions (UTRs). They also covered 96\% of CGIs from the UCSC database with additional coverage in CGI shores (0-2 kb from CGI) and CGI shelves (2-4 kb from CGI). Detailed information on the contents of the array is available in the Infinium HumanMethylation450 User Guide and Human-Methylation 450 manifest (www. 
Table 1 Basic information of six patients in this study

\begin{tabular}{|c|c|c|c|c|}
\hline Patient & Age & A (blood) & B (pericarcinous tissue) & C (pancreatic cancer tissue) \\
\hline Patient 1 (F) & 74 & $A 1^{8}$ & $\mathrm{~B} 1^{\&}$ & $\mathrm{C}^{8}$ \\
\hline Patient 2 (M) & 36 & $\mathrm{~A} 2^{2}$ & $\mathrm{~B}^{*}$ & $\mathrm{C} 2^{2}$ \\
\hline Patient 3 (M) & 66 & $A 3^{\&}$ & $\mathrm{~B}^{8}$ & $\mathrm{C}^{8}$ \\
\hline Patient 4 (F) & 60 & $\mathrm{~A} 4^{8}$ & $\mathrm{~B} 4^{*}$ & $\mathrm{C} 4^{8}$ \\
\hline Patient 5 (F) & 46 & $A 5^{8}$ & $B 5^{\&}$ & $C 5^{8}$ \\
\hline Patient 6 (F) & 71 & $A 6^{\&}$ & $B 6^{\&}$ & $\mathrm{C} 6^{8}$ \\
\hline
\end{tabular}

\&, represents qualified sample; *, represents unqualified samples. F, female; M, male.

illumina.com) and in recent papers (16). DNA methylation data were analyzed with the methylation analysis module within the BeadStudio software (Illumina Inc.). DNA methylation status of the $\mathrm{CpG}$ sites was calculated as the ratio of the signal from a methylated probe relative to the sum of both methylated and unmethylated probes. This value, known as $b$, ranges from 0 (completely unmethylated) to 1 (fully methylated). Given the batch effects normally associated with this platform and especially for small sample sizes as in the current study, we performed batch effect correction as described previously (17). For intra-chip normalization of probe intensities, colored balance and background corrections in every set of ten samples from the same chip were performed using internal control probes. $\mathrm{X}$ chromosome CpG sites in the CGIs in the AR gene in this array as well as the internal control probes were checked to validate the DNA methylation measurements.

\section{Bioinformatics}

GO enrichment analysis was performed using GOEAST (http://omicslab.genetics.ac.cn/GOEAST/index.php). Hypergeometric distribution was used to calculate the $\mathrm{P}$ value of GOID enrichment, and $\mathrm{P}<1 \mathrm{E}-4$ cut-off value was applied (18). The graph size was reduced by condensing non-significant nodes to points. The smaller the $\mathrm{P}$ value is, the more significant the GO term is enriched in the dataset. And the graph size was reduced by condensing nonsignificant nodes to points. KEGG is a database resource for understanding high-level functions and utilities of the biological system, such as the cell, the organism and the ecosystem, from molecular-level information, especially large-scale molecular datasets generated by genome sequencing and other high-through put experimental technologies (http://www.genome.jp/kegg/). We used
KOBAS software to test the statistical enrichment of differentially methylated genes in KEGG pathways.

\section{Results}

\section{Overlap of differential DNA methylation sites between pericarcinous tissues vs. cancer tissue and blood vs. pericarcinous tissues}

DNA methylation levels were compared between four pericarcinous tissues (B) vs. six pancreatic cancer tissues (C) and six blood samples (A) vs. four pericarcinous tissues (B) using Infinium HumanMethylation450 Bead Chips (Table 1). Sites simultaneously present in B versus $\mathrm{C}$ and A versus B group comparisons were group defined as hypermethylation sites. Same was done to define hypomethylation sites. Meanwhile, hypomethylation sits simultaneously existed in B vs. C group and A vs. B group was defined as hypomethylation sits. Of 485,577 CpG sites, significant diagnostic differences in DNA methylation were observed at 15,397 CpG sites representing 7,440 genes at FDR $5 \%$ correction (Figure 1 and http://fp.amegroups.cn/cms/961 4487675fcbfcb574c6af25b586775/tcr.2019.11.26-1.pdf). Of these sites, 5,605 (36.4\%, 5,605 of 15,397) CpG sites were hypomethylated and 5,870 (38.12\%, 5,870 of 15,397) $\mathrm{CpG}$ sites were hypermethylated. Functional distribution of 5,870 hypermethylated CpG sites suggested that $47.4 \%$ of these sites were located in promoter regions, $38.86 \%$ of these sites were located in gene bodies, $12.42 \%$ of these sites were located in intergenic regions and $6.01 \%$ of these sites were located in the 3'-untranslated regions (UTRs). Furthermore, sublocation analysis of 2,659 $\mathrm{CpG}$ sites in promoter region with hypermethylated indicated that $31.74 \%$ of these sites were located in regions from -200 to $-1,500 \mathrm{nt}$ upstream of the transcription start site (TSS1500), 


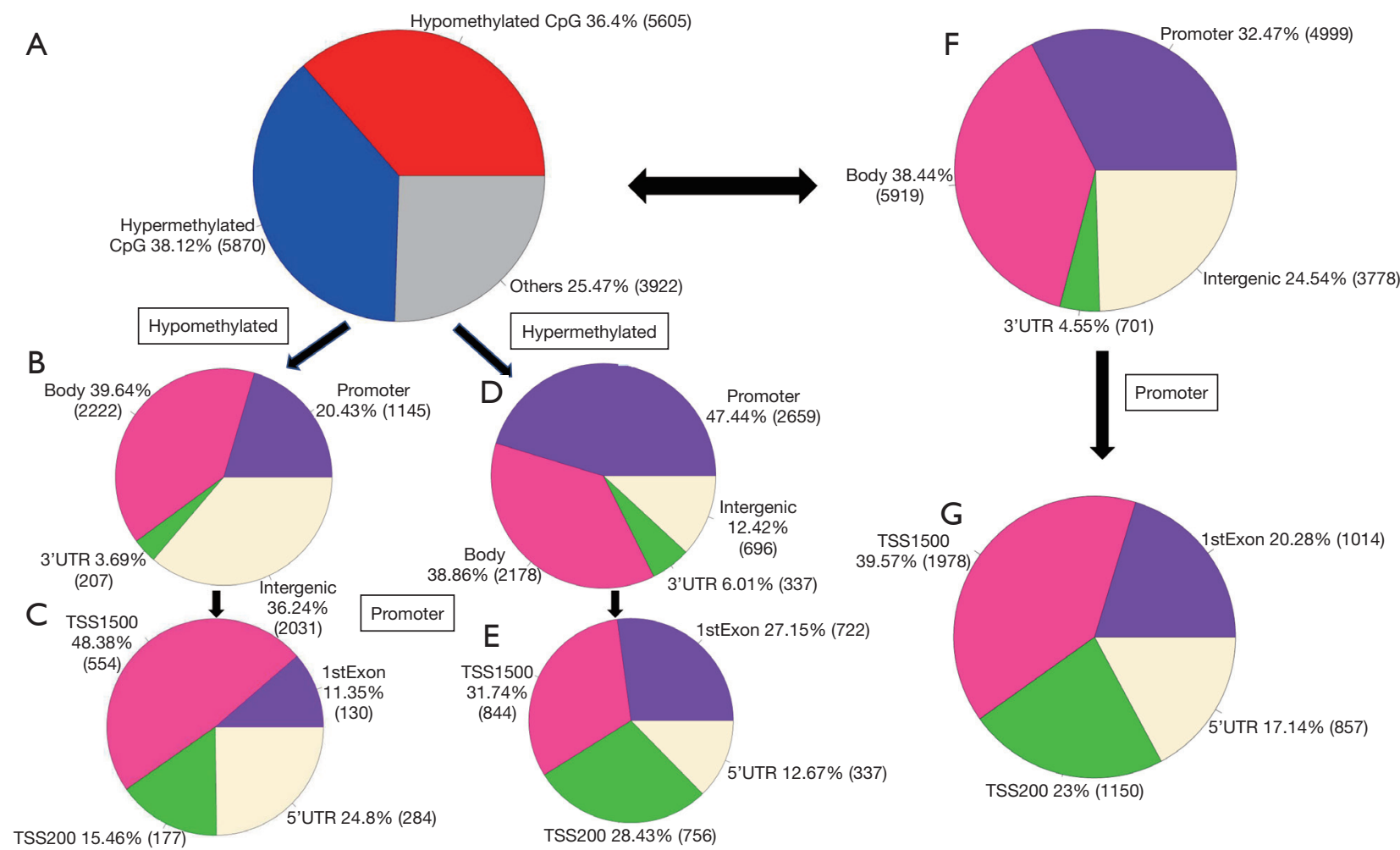

Figure 1 Graphic illustration of functional distribution and differentially methylated CpG sites identified in this study.

$28.43 \%$ of these sites were located in regions from -200 nt upstream to the TSS itself (TSS200), 27.15\% of these sites were located in 1st Exon regions and $12.67 \%$ of these sites were located in the 5'-untranslated regions (UTRs). These hypermethylated CpG sites were mostly located in gene bodies and promoter regions. Meanwhile, Functional distribution of 5,605 hypomethylated CpG sites suggested that $20.43 \%$ of these sites were located in promoter regions, $39.64 \%$ of these sites were located in gene bodies, $36.24 \%$ of these sites were located in intergenic regions and 3.69\% of these sites were located in 3'UTR regions. Furthermore, sublocation analysis of 5,605 hypomethylated CpG sites in promoter regions indicated that $48.38 \%$ of these sites were located in TSS1500 regions, $15.46 \%$ of these sites were located in TSS200 regions, $11.35 \%$ of these sites were located in 1st Exon regions and $24.8 \%$ of these sites were located in 5'UTR regions. These hypomethylated CpG sites were mostly located in gene bodies, promoter regions and intergenic regions. The results above seem to be in apparent contradiction to widely held belief that promoter hypomethylation is correlated to increased transcription and vice versa. This also indicates the possibility that transcription factors are modified which dictate their regulation of anomalous transcription in the cancer cells.

Because the 15,397 methylated CpG sites corresponded to 7,440 genes, some of the methylated genes must contain more than one methylated site. Further analysis showed that among the 7,440 methylated genes, 4,962 (67\%) possessed only one methylated site, 1,590 (21\%) contained two methylated sites, and $888(12 \%)$ contained three or more methylated sites (Figure 2 and http://fp.amegroups.cn/cms/3adcaa480666f581 911c4ab936783571/tcr.2019.11.26-2.pdf). In particular, one methylated gene (PTPRN2) possessed 40 methylated sites in overlap. Meanwhile, the MAD1 mitotic arrest deficient-like 1 (yeast) (MAD1L1, ENSG00000002822) possessed over 25 methylated sites (Figure 3). Of note, number of methylation sites can be correlated to gene length and mere presence of more methylation sites does not mean increased methylationbased regulation. Instead, methylation sites normalized over gene length is a better indicator of propensity to regulation by methylation.

\section{Gene Ontology (GO) and KEGG pathway analysis of differentially methylated genes in overlap group}

In order to improve the credibility of this research, the 
genes with counts of methylation sites were equal or greater than 15 were selected to perform intensive study. After such screening, 10 genes with more than three counts of differentially methylated $\mathrm{CpG}$ sites were harvested. GO terms were further assigned to Homo sapiens differentially methylated genes based on their sequence similarities to known proteins in the UniProt database annotated with GO terms as well as InterPro and Pfam domains they contain. GO annotation and enrichment analysis of ten significantly differentially methylated genes was implemented by GOEAST software (http://omicslab. genetics.ac.cn/GOEAST/index.php), in which gene length bias was corrected. GO terms with corrected $\mathrm{P}$ value less than $10^{-4}$ were considered significantly enriched (Figure 4). Biological processes, cellular components, and molecular functions are shown in Figure 4 and Table S2. From the perspective of biological processes, there are 75 GO terms were assigned under this catalogues. Among these terms,

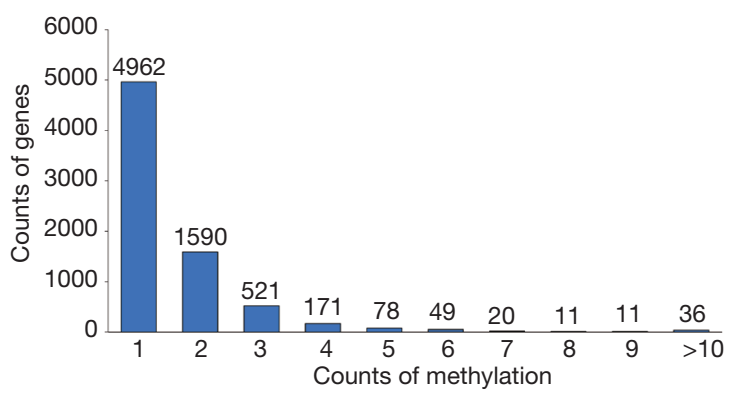

Figure 2 Analysis of the identified methylated $\mathrm{CpG}$ sites. Distribution of the methylated $\mathrm{CpG}$ sites in the methylated genes. spindle checkpoint (GO: 0031577, P value: 8.98E-21), mitotic spindle assembly checkpoint (GO: 0007094, P value: $3.5 \mathrm{E}-21)$ and negative regulation of mitotic sister chromatid segregation (GO: $0033048, \mathrm{P}$ value: $3.5 \mathrm{E}-21$ ) were the top three significantly enriched terms. From the cellular component perspective, there are $3 \mathrm{GO}$ terms were assigned under this catalogues. Among these terms, A band (GO: 0031672, P value: 1.1E-05) was the top significantly enriched terms. From the molecular function perspective, there are 4 GO terms were assigned under this catalogues. Among these terms, G-protein beta/gamma-subunit complex binding (GO: 0031683 , P value: $2.4 \mathrm{E}-11$ ) was the top significantly over-represented terms.

In vivo, various biological functions were implemented by cooperation of different genes. Pathways enrichment analysis can give some clues to the biochemical and signal transduction pathways that differentially expressed genes may participate in. KEGG is a database resource for understanding high-level functions and utilities of the biological system, such as the cell, the organism and the ecosystem, from molecular-level information, especially large-scale molecular datasets generated by genome sequencing and other high-through put experimental technologies (http://www.genome.jp/kegg/). We used KOBAS software to test the statistical enrichment of differentially methylated genes in KEGG pathways (19). In this study, ten significantly differentially methylated genes involve 52 pathways (Table S3). It was worthy noticed that 43 pathways owned the same corrected $\mathrm{P}$ value $(0.31)$. Table $S 3$ shows the results of pathways enrichment, it clearly displays that vibrio cholerae infection were the top enriched

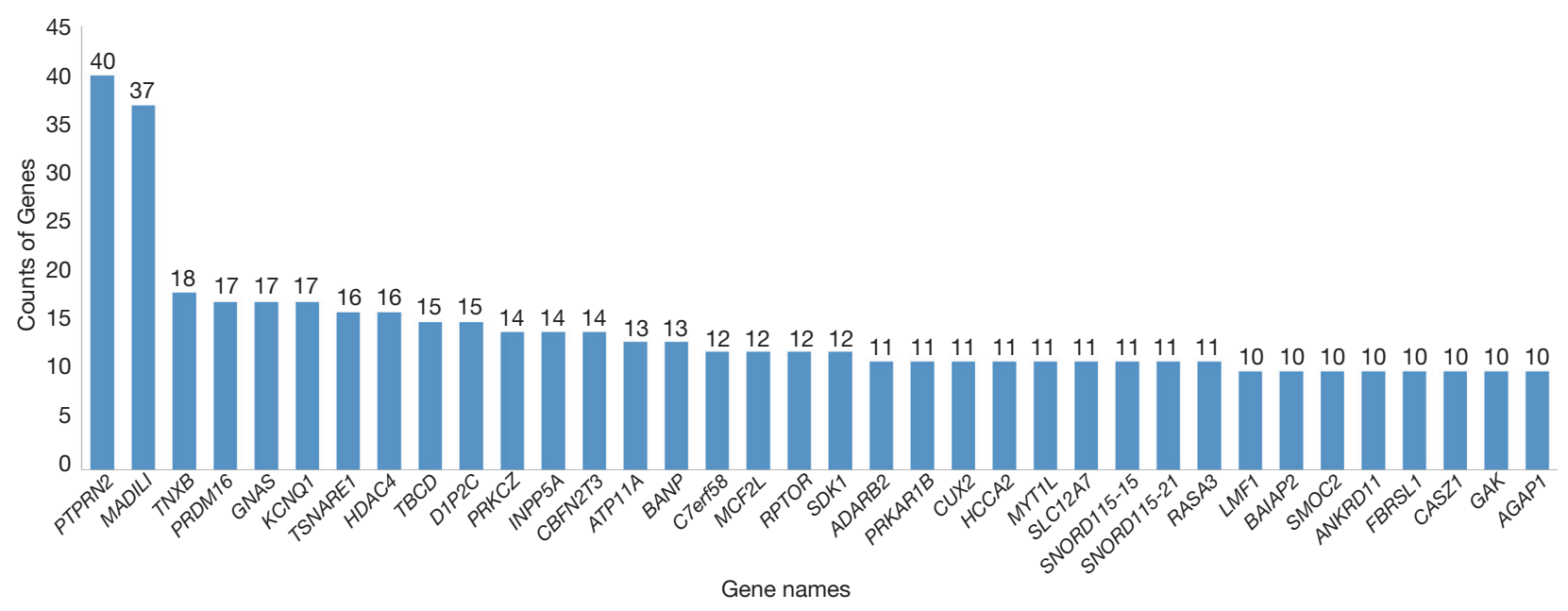

Figure 3 Methylated genes with over ten methylated CpG sites. 

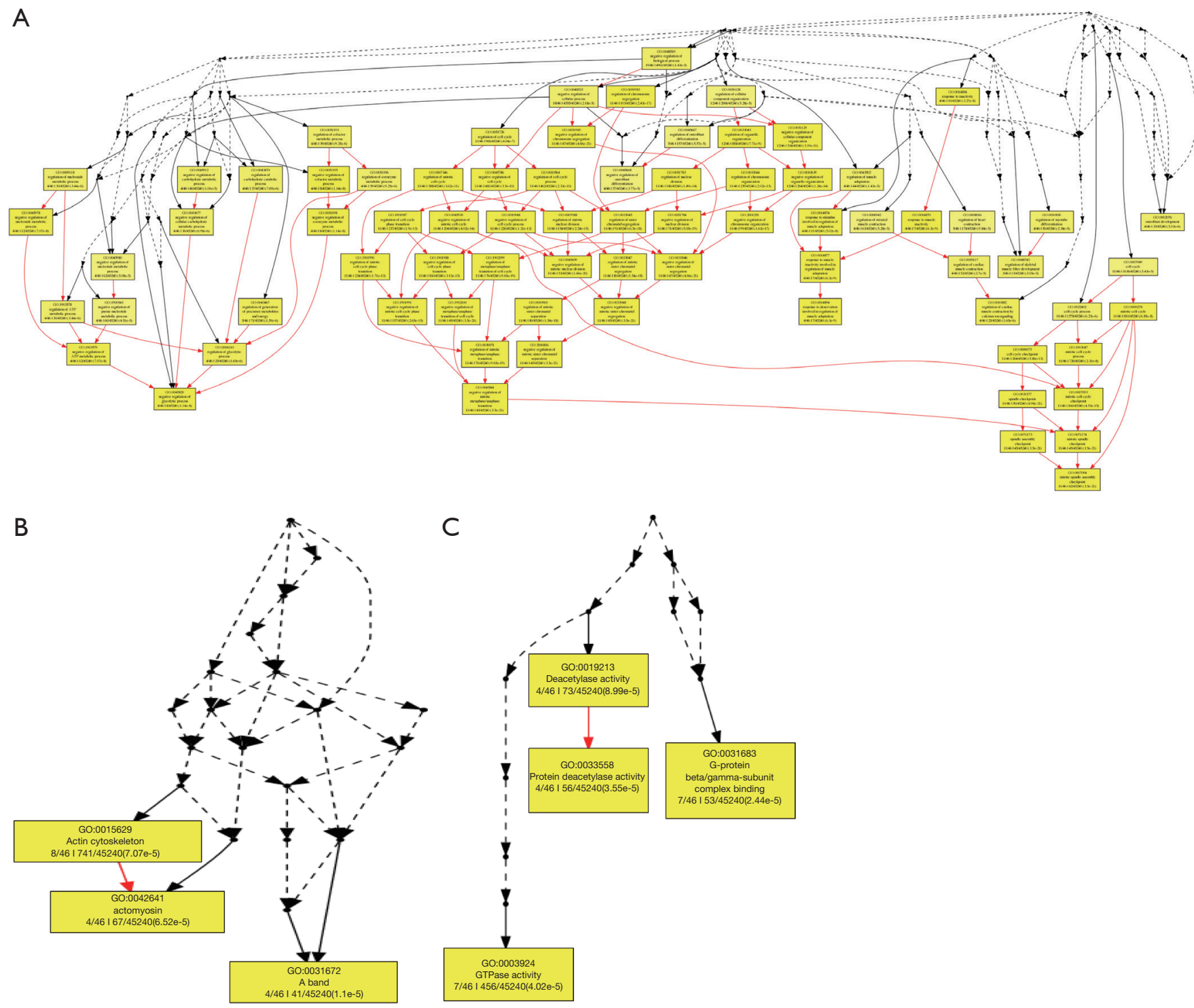

Figure 4 GO enrichment analysis of ten significant differentially methylated genes ( $\geq 15$ methylated CpG sites). The figure is composed of three parts: "biological processes (BP, Figure 4A)", "molecular functions (MF, Figure 4B)", and "cellular components (CC, Figure 4C)". Hypergeometric statistical test methods were used for analysis, and the significance level of enrichment was set at $\mathrm{P}$ value $<10-4$. Black solid lines symbolize the connections between enriched terms. The boxes contain GO functional positioning that is equivalent to the significant GO terms. GO, Gene Ontology.

term. Two differentially methylated genes that identified in our study participate in this pathway. Moreover, it is worth noting that pancreatic secretion, type I diabetes mellitus, Insulin secretion and Adrenergic signaling in cardiomyocytes were also significant enriched in this study. The pathways mentioned above were adopted with the function that pancreas played.

\section{GO and KEGG pathway analysis of differentially methylated sites located in promoter regions of genes in overlap group}

The promoter contains specific DNA sequences that are recognized by proteins known as transcription factors. These factors bind to the promoter sequences, recruiting RNA polymerase, the enzyme that synthesizes the RNA 


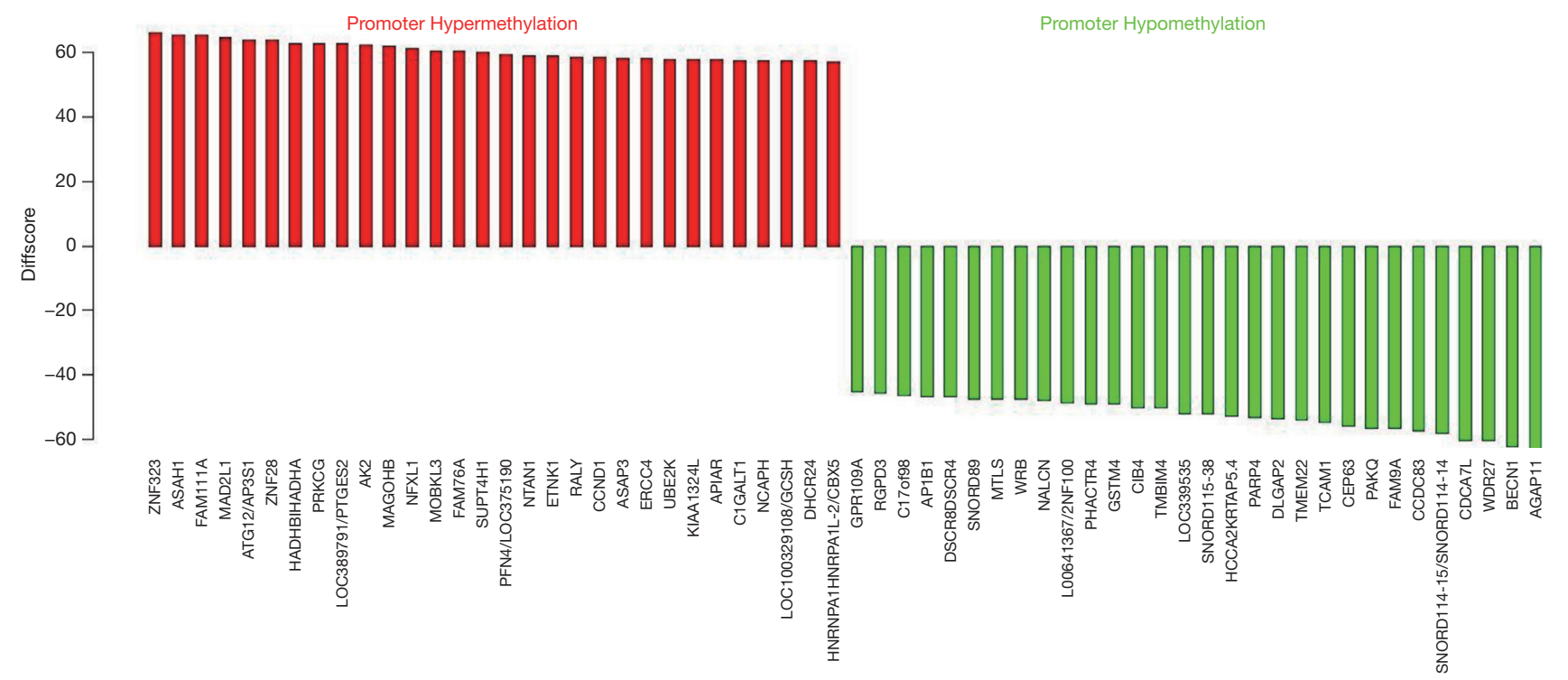

Figure 5 Sixty candidate genes with hypermethylation and hypomethylation status.

from the coding region of the gene. Eukaryotic promoters are extremely diverse and are difficult to characterize. They typically lie upstream of the gene and can have regulatory elements several kilobases away from the transcriptional start site. In eukaryotes, the transcriptional complex can cause the DNA to bend back on itself, which allows for placement of regulatory sequences far from the actual site of transcription. Many eukaryotic promoters, contain a TATA box (sequence TATAAA), which in turn binds a TATA binding protein which assists in the formation of the RNA polymerase transcriptional complex. Of this study, we identified 4,999 differentially methylated sites located in promoter regions in overlap group (http://fp.amegroups.cn/ cms/24bc751fdb7f41b7ce54e74bde803221/tcr.2019.11.263.pdf). Moreover, we picked out 30 genes with significantly hypermethylation and 30 genes with significantly hypomethylation in the overlap group (Figure 5 and Table S4). GO and KEGG analysis were performed with these 60 aberrant methylation genes. Of the GO analysis (Figure 6 and Table S5), GO terms with corrected $\mathrm{P}$ value less than $10^{-4}$ were considered significantly enriched. From the perspective of biological processes, there are three GO terms were assigned under this catalogues. Among these terms, autophagosome assembly (GO: 0000045, $\mathrm{P}$ value: 5.8E-05), autophagy (GO: 0006914, P value: $3.8 \mathrm{E}-10$ ) and autophagosome organization (GO: 1905037, $\mathrm{P}$ value: $5.8 \mathrm{E}-05)$ were the top three significantly enriched terms. From the cellular component perspective, there are three
GO terms were assigned under this catalogues. Among these terms, mitochondrial fatty acid beta-oxidation multienzyme complex (GO: 0016507, P value: 6.4E-07), fatty acid betaoxidation multienzyme complex (GO: 0036125, P value: 6.4E-07) and glycine cleavage complex (GO: 0005960, P value: $6.4 \mathrm{E}-07$ ) were the top three significantly enriched terms. From the molecular function perspective, there are five GO terms were assigned under this catalogues. Among these terms, long-chain-3-hydroxyacyl-CoA dehydrogenase activity (GO: 0016509, $\mathrm{P}$ value: $6.4 \mathrm{E}-07$ ) was the top significantly over-represented terms. Of the KEGG analysis (Table S6), it clearly displays that Regulation of autophagy were the top enriched term. Two differentially methylated genes that identified in our study participate in this pathway. Moreover, it is worth noting that Non-small cell lung cancer, Glioma, ErbB signaling pathway and Fc gamma R-mediated phagocytosis were also significant enriched in this study.

\section{Methylation status of key genes related to pancreatic cancer}

To pinpoint the methylation status of pancreatic cancer related genes (Table 2). We check out 22 pancreatic cancer related genes, including ERBB2, $A K T 1, C D C 42$, KRAS, RAC1, RALB, RALA, PIK3R3, PIK3R2, AKT2, PLD1, RALBP1, SMAD4, RAF1, SMAD3, SMAD2, RB1, MAPK10, BAD, CDK4, STAT3 and CCND1, which has been reported before. The results indicated that $E R B B 2$, KRAS, PIK3R3, PLD1, RALBP1, RB1 and MAPK10 all 

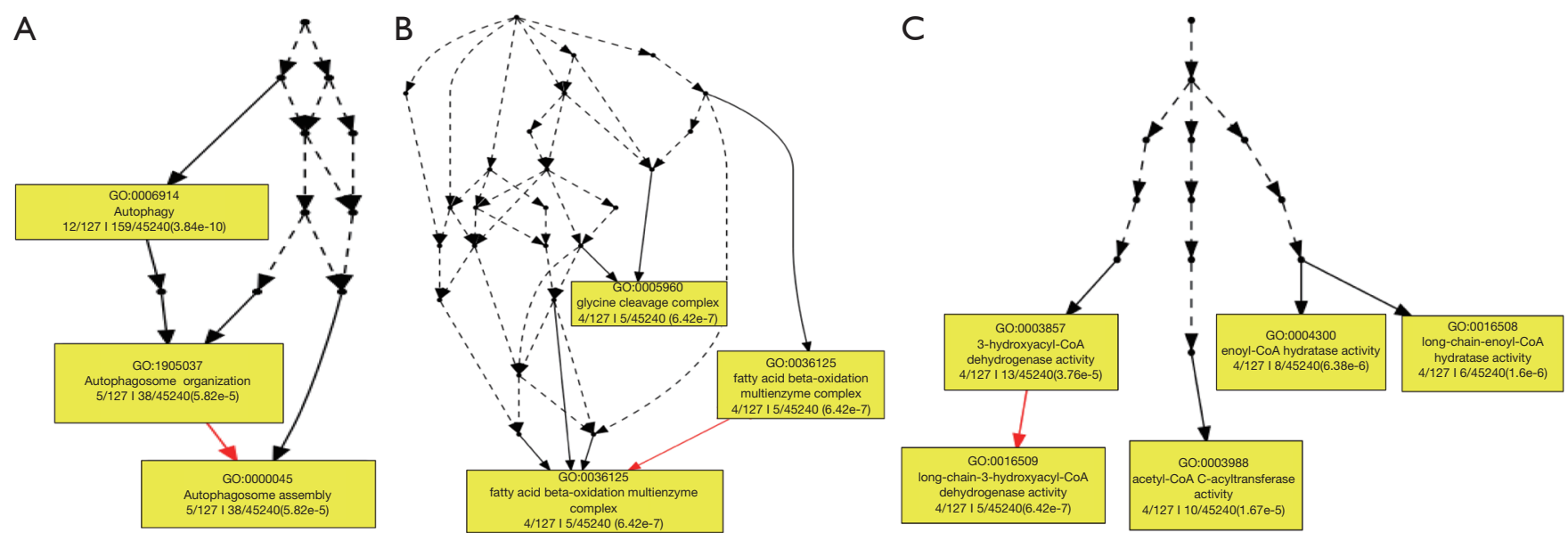

Figure $6 \mathrm{GO}$ enrichment analysis of 60 candidate genes with hypermethylation and hypomethylation status. The figure is composed of three parts: "biological processes (BP, Figure 6A)", "molecular functions (MF, Figure 6B)", and "cellular components (CC, Figure 6C)". Hypergeometric statistical test methods were used for analysis, and the significance level of enrichment was set at $\mathrm{P}$ value $<10-4$. Black solid lines symbolize the connections between enriched terms. The boxes contain GO functional positioning that is equivalent to the significant GO terms. GO, Gene Ontology.

showed hypomethylation status. On the contrary, the other genes all showed hypermethylation status. Of note, effect size estimation was not calculated in this case.

\section{Discussion}

It is now evident that epigenetic abnormalities are extremely common in cancers, and these abnormalities provide an alternative mechanism of transcriptional silencing. Epigenetic abnormalities in cancer predominantly encompass methylation of CG dinucleotides (CpG islands) in the 5' regulatory region of tumor suppressor genes, which abrogates RNA polymerase from binding and initiating transcription. In cancers, there is preferential methylation of the gene promoter, but not in the corresponding normal cells within the tissue of origin. Methylome sequencing, without a priori bias to known $\mathrm{CpG}$ islands, yielded novel highly discriminant methylation markers for pancreatic cancer. Importantly, these findings were confirmed using an independent sample set of tumor and control tissues, showing that the method used in this study successfully identify pancreatic cancer markers with low background levels. Many of the markers with the strongest association to pancreatic cancer also showed greater than 10-fold increases in the median copies per sample compared with controls; this observation is critical to the application of these markers in diagnostic test development where assays must detect tumor signal against the background biologic milieu. Novel candidates identified by this method were clinically piloted by assay from pancreatic juice, demonstrating utility for the detection of pancreatic cancer in blinded comparisons, even to diseased controls with chronic pancreatitis.

In this study, genome-wide DNA methylation profiling was conducted between four pericarcinous tissues $v s$. six pancreatic cancer tissues and six blood samples $v$ s. four pericarcinous tissues using Infinium HumanMethylation450 Beadchips. Sampling from pancreatic cancer tissues, pericarcinous tissues and blood of one patient is a useful method for investigating DNA methylation biomarkers without the influence of genetic discordance. Actually, the approach used in this study has identified vagarious epigenetic differences, including non-small cell lung cancer (20), colorectal carcinoma (21) and hepatocellular carcinoma (22), etc. Of this study, a total of 15,397 differentially methylated CpG sites (3.2\%, of 485,577 CpG sites,) corresponding 7,440 genes that were identified in overlap. Of these $15,397 \mathrm{CpG}$ sites with significant diagnostic differences in DNA methylation, 5,605 (36.4\%, 5,605 of 15,397) CpG sites were hypomethylated and 5,870 (38.12\%, 5,870 of 15,397) $\mathrm{CpG}$ sites were hypermethylated. Functional distribution of 5,870 hypermethylated CpG sites suggested that $47.4 \%$ of these sites were located in promoter regions, $38.86 \%$ of these sites were located in gene bodies, $12.42 \%$ of these 
Table 2 Methylation status of key genes related to pancreatic cancer

\begin{tabular}{|c|c|c|c|}
\hline \multirow{2}{*}{ Series number } & \multirow{2}{*}{ Gene } & \multicolumn{2}{|c|}{ Methylation status } \\
\hline & & Hypermethylation & Hypomethylation \\
\hline 1 & ERBB2 & N/A & Yes \\
\hline 2 & $A K T 1$ & Yes & N/A \\
\hline 3 & CDC42 & Yes & N/A \\
\hline 4 & KRAS & N/A & Yes \\
\hline 5 & RAC1 & Yes & N/A \\
\hline 6 & $R A L B$ & Yes & N/A \\
\hline 7 & $R A L A$ & Yes & $\mathrm{N} / \mathrm{A}$ \\
\hline 8 & PIK3R3 & $\mathrm{N} / \mathrm{A}$ & Yes \\
\hline 9 & AKT2 & Yes & N/A \\
\hline 10 & PIK3R2 & Yes & N/A \\
\hline 11 & PLD1 & N/A & Yes \\
\hline 12 & $R A L B P 1$ & N/A & Yes \\
\hline 13 & SMAD4 & Yes & N/A \\
\hline 14 & $R A F 1$ & Yes & N/A \\
\hline 15 & SMAD3 & Yes & N/A \\
\hline 16 & SMAD2 & Yes & N/A \\
\hline 17 & $R B 1$ & $\mathrm{~N} / \mathrm{A}$ & Yes \\
\hline 18 & MAPK10 & N/A & Yes \\
\hline 19 & $B A D$ & Yes & $\mathrm{N} / \mathrm{A}$ \\
\hline 20 & CDK4 & Yes & N/A \\
\hline 21 & STAT3 & Yes & N/A \\
\hline 22 & CCND1 & Yes & N/A \\
\hline
\end{tabular}

sites were located in intergenic regions and $6.01 \%$ of these sites were located in the 3'-untranslated regions (UTRs). Furthermore, sublocation analysis of 2,659 CpG sites in promoter region with hypermethylated indicated that $31.74 \%$ of these sites were located in regions from -200 to $-1,500 \mathrm{nt}$ upstream of the transcription start site (TSS1500), $28.43 \%$ of these sites were located in regions from $-200 \mathrm{nt}$ upstream to the TSS itself (TSS200), 27.15\% of these sites were located in 1st Exon regions and $12.67 \%$ of these sites were located in the 5'-untranslated regions (UTRs). These hypermethylated $\mathrm{CpG}$ sites were mostly located in gene bodies and promoter regions. Meanwhile, Functional distribution of 5,605 hypomethylated $\mathrm{CpG}$ sites suggested that $20.43 \%$ of these sites were located in promoter regions, $39.64 \%$ of these sites were located in gene bodies,
$36.24 \%$ of these sites were located in intergenic regions and $3.69 \%$ of these sites were located in 3'UTR regions. Furthermore, sublocation analysis of 5,605 hypomethylated CpG sites in promoter regions indicated that $48.38 \%$ of these sites were located in TSS1500 regions, $15.46 \%$ of these sites were located in TSS200 regions, $11.35 \%$ of these sites were located in 1st Exon regions and 24.8\% of these sites were located in 5'UTR regions. This seems to be consistent with previous findings that methylation of these regions inhibits transcription. For example, Irizarry et al. demonstrated that altered DNA methylation in cancer occurred in CGI shores rather than in the CGIs, and DNA methylation changes in CGI shores were strongly related to gene expression (23). In addition, we had noticed that numerous differential CpG sites were located in gene bodies. Recently, it became apparent that CGIs in gene bodies act as alternative promoters $(24,25)$ and that tissuespecific or cell type-specific CGI methylation is prevalent in gene bodies (26). GO analysis of these significantly differentially methylated genes revealed that spindle checkpoint, mitotic spindle assembly checkpoint and negative regulation of mitotic sister chromatid segregation were the top three significantly enriched terms from perspective of biological processes. Meanwhile, from the cellular component perspective, there are 3 GO terms were assigned under this catalogues. Among these terms, A band was the top significantly enriched terms. In addition, from the molecular function perspective, there are 4 GO terms were assigned under this catalogues. Among these terms, G-protein beta/gamma-subunit complex binding was the top significantly over-represented terms. KEGG analysis showed that vibrio cholerae infection was the top enriched term. Moreover, pancreatic secretion, Type I diabetes mellitus, Insulin secretion and Adrenergic signaling in cardiomyocytes were also significant enriched in this study. Furthermore, GO analysis of differentially methylated sites located in promoter regions of genes showed that autophagosome assembly, autophagy and autophagosome organization were the top three significantly enriched terms from the perspective of biological processes. From the cellular component perspective, there are three GO terms were assigned under this catalogues. Among these terms, mitochondrial fatty acid beta-oxidation multienzyme complex, fatty acid beta-oxidation multienzyme complex and glycine cleavage complex were the top three significantly enriched terms. From the molecular function perspective, long-chain-3-hydroxyacyl-CoA dehydrogenase activity was the top significantly over-represented terms. Of 
the KEGG analysis, it clearly displays that Regulation of autophagy were the top enriched term. It is worth noting that Non-small cell lung cancer, Glioma, ErbB signaling pathway and $\mathrm{Fc}$ gamma $\mathrm{R}$-mediated phagocytosis were also significant enriched in this study. Meanwhile, we have invested methylation status of 22 pancreatic cancer related key genes, and revealed the aberrant methylation status. For example, Cyclin D1 (CCND1) has been showed to be overexpressed in human pancreatic cancer (27). Here, CCND1 was identified as hypermethylated candidate gene that is inconsistent with a previous study (28), which suggested that over-expression of cyclin D1 in pancreatic cancer is associated with the loss of methylation.

There are several limitations to the present study. First, the sample size was not large. Further validation in studies encompassing more samples is warranted in the future. Second, the analyzed CpG sites were limited in number, although the $450 \mathrm{~K}$ microarray is one of the most powerful and cost-effective tools currently available for assessing methylation changes. Third, it is not possible to differentiate methylation from 5-hydroxymethylation of cytosine, which also plays a critical role in gene regulation (29). In summary, aberrant DNA methylation in pancreatic cancer tissues was identified at numerous CpG sites across the whole genome in using two independent sets of samples. Of the differently methylated $\mathrm{CpG}$ sites in the CGIs, most of them were located in the promoter regions. These findings support the hypothesis that altered DNA methylation could be involved in the pathophysiology of pancreatic cancer. Although the number of analyzed individuals was limited, the analysis was sufficient to provide DNA methylation distribution patterns across different genomic regions that were largely in agreement with patterns previously observed. The methylome data alone was sufficient for correctly distinguishing between all the ten tissues studied, collectively demonstrating that tissues are characterized by distinctive methylation patterns that reflect their tissue-specific functions. Our study provoked the question, of how differentially methylated CpG sites mechanistically contribute to the gene functions, especially for the numerous methylation regions that were found in gene body areas. In addition, it remains unclear, however, how the gene body differentially methylated CpG sites may function as regulators of gene expression, and this question should be addressed in the future epigenetic studies.

In conclusion, previous studies have demonstrated that DNA methylation play important roles in the regulation of developmental processes of several cancers. The identification of differentially methylated genes in this study provides information valuable to the in-depth study of pancreatic cancer. Moreover, the results of this study will not only improve our understanding of the differentially methylated genes but will also help to enhance methylome studies of pancreatic cancer.

\section{Acknowledgments}

We also thanks for native English expert in Medical Communications Department in Fresta Technologies Co, Ltd. (www.4upub.com) to polish the language.

Funding: This study was supported by the National Natural Science Foundation of China (No. 81170494), Natural Science Foundation of Beijing (No.7162176) and Beijing Nova program (Z171100001117112, Z121107002512122), Translational Medicine Program of Chinese PLA General Hospital (2017TM-022), and Youth Talents Promotion Project (17-JCJQ-QT-030).

\section{Footnote}

Conflicts of Interest: The authors have completed the ICMJE uniform disclosure form (available at http://dx.doi. org/10.21037/tcr.2019.11.26). The authors have no conflicts of interest to declare.

Ethical Statement: The authors are accountable for all aspects of the work in ensuring that questions related to the accuracy or integrity of any part of the work are appropriately investigated and resolved. The study was conducted in accordance with the Declaration of Helsinki (as revised in 2013). This study was approved by the Ethics Committee of Chinese General Hospital of PLA. All patients provided signed informed consent.

Open Access Statement: This is an Open Access article distributed in accordance with the Creative Commons Attribution-NonCommercial-NoDerivs 4.0 International License (CC BY-NC-ND 4.0), which permits the noncommercial replication and distribution of the article with the strict proviso that no changes or edits are made and the original work is properly cited (including links to both the formal publication through the relevant DOI and the license). See: https://creativecommons.org/licenses/by-nc-nd/4.0/.

\section{References}

1. Jemal A, Siegel R, Ward E, et al. Cancer statistics, 2008. 
CA Cancer J Clin 2008;58:71-96.

2. Li D, Xie K, Wolff R, et al. Pancreatic cancer. Lancet 2004;363:1049-57.

3. Hassan MM, Bondy ML, Wolff RA, et al. Risk factors for pancreatic cancer: case-control study. Am J Gastroenterol 2007;102:2696-707.

4. Batty GD, Kivimaki M, Morrison D, et al. Risk factors for pancreatic cancer mortality: extended follow-up of the original Whitehall Study. Cancer Epidemiol Biomarkers Prev 2009;18:673-5.

5. Landi S. Genetic predisposition and environmental risk factors to pancreatic cancer: A review of the literature. Mutat Res 2009;681:299-307.

6. Hartwig $W$, Strobel O, Hinz U, et al. CA19-9 in potentially resectable pancreatic cancer: perspective to adjust surgical and perioperative therapy. Ann Surg Oncol 2013;20:2188-96.

7. Kim JE, Lee KT, Lee JK, et al. Clinical usefulness of carbohydrate antigen 19-9 as a screening test for pancreatic cancer in an asymptomatic population. J Gastroenterol Hepatol 2004;19:182-6.

8. Petronis A, Gottesman, II, Crow TJ, et al. Psychiatric epigenetics: a new focus for the new century. Mol Psychiatry 2000;5:342-6.

9. Yi JM, Guzzetta AA, Bailey VJ, et al. Novel methylation biomarker panel for the early detection of pancreatic cancer. Clin Cancer Res 2013;19:6544-55.

10. Jiao L, Zhu J, Hassan MM, et al. K-ras mutation and p16 and preproenkephalin promoter hypermethylation in plasma DNA of pancreatic cancer patients: in relation to cigarette smoking. Pancreas 2007;34:55-62.

11. Alvarez H, Opalinska J, Zhou L, et al. Widespread hypomethylation occurs early and synergizes with gene amplification during esophageal carcinogenesis. PLoS Genet 2011;7:e1001356.

12. Nones K, Waddell N, Song S, et al. Genome-wide DNA methylation patterns in pancreatic ductal adenocarcinoma reveal epigenetic deregulation of SLIT-ROBO, ITGA2 and MET signaling. Int J Cancer 2014;135:1110-8.

13. Ehrlich M. DNA methylation in cancer: too much, but also too little. Oncogene 2002;21:5400-13.

14. Feinberg AP, Gehrke CW, Kuo KC, et al. Reduced genomic 5-methylcytosine content in human colonic neoplasia. Cancer Res 1988;48:1159-61.

15. Dedeurwaerder S, Defrance M, Calonne E, et al. Evaluation of the Infinium Methylation $450 \mathrm{~K}$ technology. Epigenomics 2011;3:771-84.

16. Sandoval J, Heyn H, Moran S, et al. Validation of a DNA methylation microarray for $450,000 \mathrm{CpG}$ sites in the human genome. Epigenetics 2011;6:692-702.

17. Sun Z, Chai HS, Wu Y, et al. Batch effect correction for genome-wide methylation data with Illumina Infinium platform. BMC Med Genomics 2011;4:84.

18. Zheng Q, Wang XJ. GOEAST: a web-based software toolkit for Gene Ontology enrichment analysis. Nucleic Acids Res 2008;36:W358-63.

19. Mao X, Cai T, Olyarchuk JG, et al. Automated genome annotation and pathway identification using the KEGG Orthology $(\mathrm{KO})$ as a controlled vocabulary. Bioinformatics 2005;21:3787-93.

20. Wang LG, Ni Y, Su BH, et al. MicroRNA-34b functions as a tumor suppressor and acts as a nodal point in the feedback loop with Met. Int J Oncol 2013;42:957-62.

21. Jin S, Mu Y, Wang X, et al. Overexpressed RACK1 is positively correlated with malignant degree of human colorectal carcinoma. Mol Biol Rep 2014;41:3393-9.

22. Wang Z, Zhang L, Zhang D, et al. Glycolysis inhibitor 2-deoxy-D-glucose suppresses carcinogen-induced rat hepatocarcinogenesis by restricting cancer cell metabolism. Mol Med Rep 2015;11:1917-24.

23. Irizarry RA, Ladd-Acosta C, Wen B, et al. The human colon cancer methylome shows similar hypo- and hypermethylation at conserved tissue-specific $\mathrm{CpG}$ island shores. Nat Genet 2009;41:178-86.

24. Illingworth RS, Gruenewald-Schneider U, Webb S, et al. Orphan $\mathrm{CpG}$ islands identify numerous conserved promoters in the mammalian genome. PLoS Genet 2010;6:e1001134.

25. Maunakea AK, Nagarajan RP, Bilenky M, et al. Conserved role of intragenic DNA methylation in regulating alternative promoters. Nature 2010;466:253-7.

26. Deaton AM, Webb S, Kerr AR, et al. Cell type-specific DNA methylation at intragenic $\mathrm{CpG}$ islands in the immune system. Genome Res 2011;21:1074-86.

27. Ebert MP, Hernberg S, Fei G, et al. Induction and expression of cyclin D3 in human pancreatic cancer. J Cancer Res Clin Oncol 2001;127:449-54.

28. Gansauge S, Gansauge F, Ramadani, $M$ et al. Overexpression of cyclin D1 in human pancreatic carcinoma is associated with poor prognosis. Cancer Res 1997;57:1634-7.

29. Bhutani N, Burns DM, Blau HM. DNA demethylation dynamics. Cell 2011;146:866-72.

Cite this article as: Wang H, Yin F, Yuan F, Men Y, Deng M, Liu Y, Li Q. Pancreatic cancer differential methylation atlas in blood, peri-carcinomatous and diseased tissue. Transl Cancer Res 2020;9(2):421-431. doi: 10.21037/tcr.2019.11.26 
Supplementary

Table S1 Clinicopathological details of patients

\begin{tabular}{lccl}
\hline Patient No. & Age & Gender & Histology \\
\hline 1 & F & 74 & Highly differentiated ductal adenocarcinoma \\
2 & M & 36 & Poorly differentiated adenocarcinoma \\
3 & M & 66 & Moderately differentiated adenocarcinoma \\
4 & F & 60 & Moderately differentiated ductal adenocarcinoma \\
5 & F & 46 & Moderately differentiated ductal adenocarcinoma \\
6 & F & 71 & Moderately-poorly differentiated adenocarcinoma \\
\hline
\end{tabular}

F, female; M, male. 


\begin{tabular}{|c|c|c|c|c|c|c|c|c|c|c|c|}
\hline 6010 & $\begin{array}{l}\text { Ontology } \\
\text { silogical } \\
\text { procoss }\end{array}$ & $\begin{array}{l}\text { Term } \\
\text { Negative regulation of biological process }\end{array}$ & Level & & $\frac{m}{4,961 \quad 4}$ & $\frac{t}{45,240}$ & 46 & 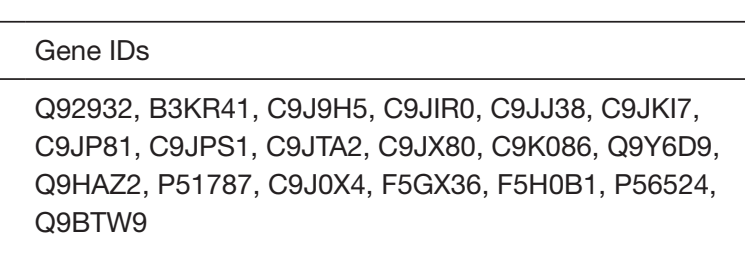 & 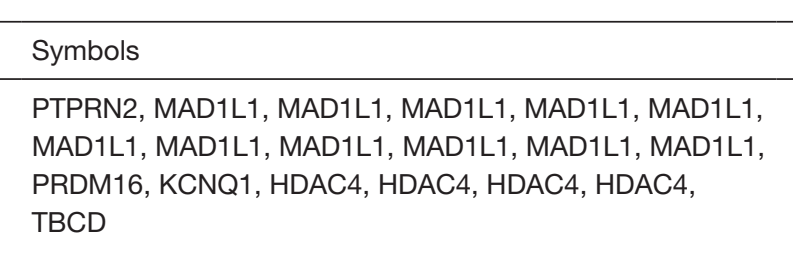 & $\frac{\text { Log odds ratio }}{1.913262}$ & $\frac{P}{1.42711 E-0 .}$ \\
\hline :0000075 & $\begin{array}{l}\text { Bilogical } \\
\text { arocoss }\end{array}$ & Cell cycle checkpoint & 3 & 11 & 264 & 45,240 & 46 & 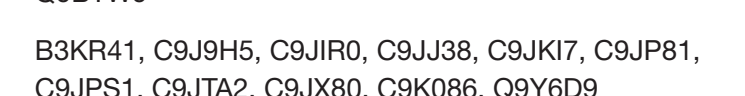 & 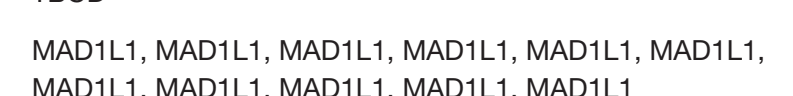 & 5.356787 & 5.862665-1 \\
\hline o: 0000278 & $\begin{array}{c}\text { Biological } \\
\text { procoss }\end{array}$ & Mitotic cell yycle & ${ }^{2}$ & 11 & 810 & 45,240 & 46 & 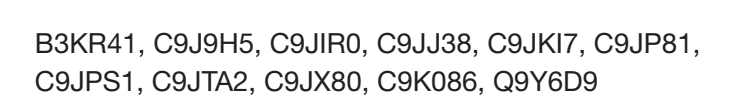 & 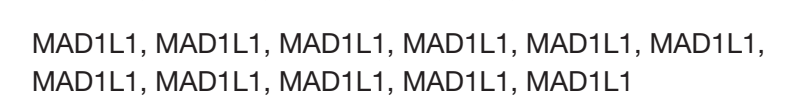 & 3.739403 & 6.84714E \\
\hline :0:0007499 & $\begin{array}{c}\text { Biological } \\
\text { procoss }\end{array}$ & Cell yycle & 2 & 11 & 1,636 4 & 45,240 & 46 & 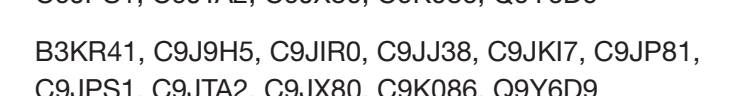 & 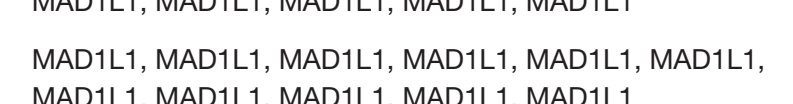 & 2.7252524 & 5.433994E-0: \\
\hline 0:0007088 & $\begin{array}{c}\text { Biological } \\
\text { procoss }\end{array}$ & Reguation of mitotic nuclear division & 4 & 11 & 154 & 45,240 & 46 & 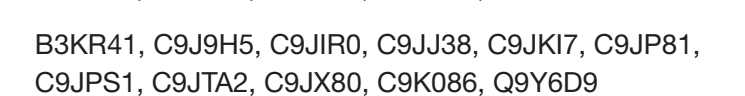 & 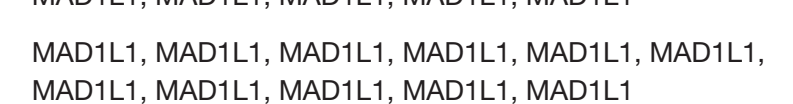 & 6.1343394 & 2.24109E- \\
\hline :0:0007093 & $\begin{array}{c}\text { Biological } \\
\text { procoss }\end{array}$ & Mitotic cell cycle checkpoint & 7 & 11 & 166 & 45,240 & 46 & 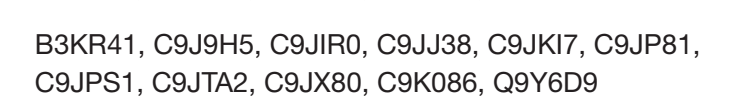 & 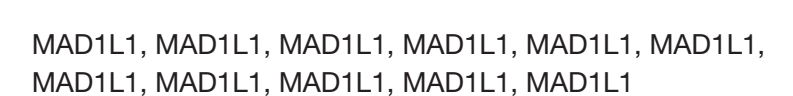 & 6.026142 & 4.531544- \\
\hline 0:0077094 & $\begin{array}{c}\text { Biological } \\
\text { procoss }\end{array}$ & Mitotic spindle assembly checkpoint & 13 & 11 & 42 & 45,240 & 46 & 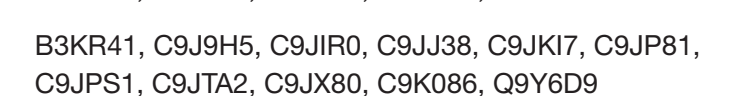 & 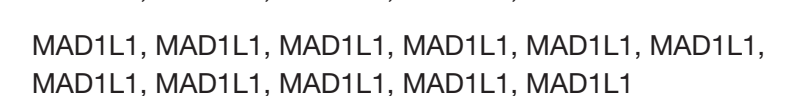 & 8.008664 & 3.49706E-3-3 \\
\hline o:0007346 & $\begin{array}{c}\text { Biological } \\
\text { procoss }\end{array}$ & Regulation of mitotic cell yycle & ${ }^{2}$ & 11 & 388 & 45,240 & 46 & 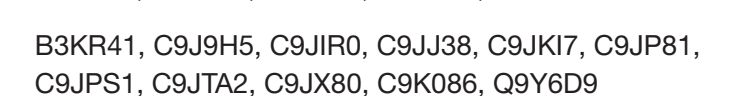 & 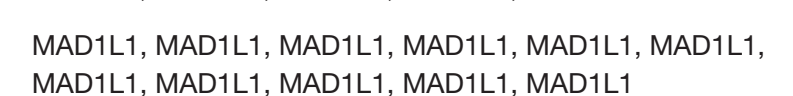 & 4.801268 & 3.61966-1 \\
\hline 0:0010564 & $\begin{array}{c}\text { Biological } \\
\text { pricoss }\end{array}$ & Reguation of cell cycle processs & ${ }^{2}$ & 11 & 462 & 45,240 & 46 & 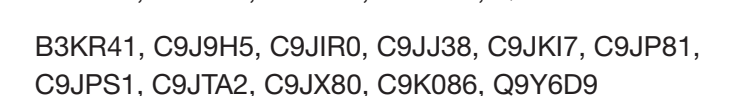 & 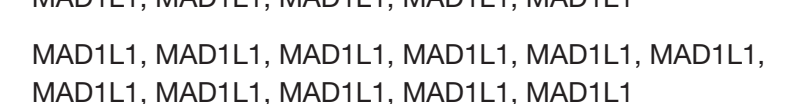 & 4.594932 & $2.32842 E-\mathrm{K}$ \\
\hline 0:0010639 & $\begin{array}{l}\text { Logical } \\
\text { cosss }\end{array}$ & Negative regulation of organelle organization & ${ }^{5}$ & 12 & 264 & 45,240 & 46 & 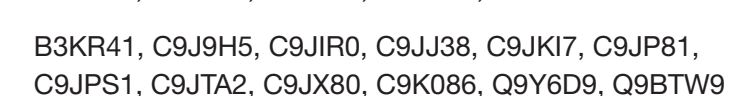 & 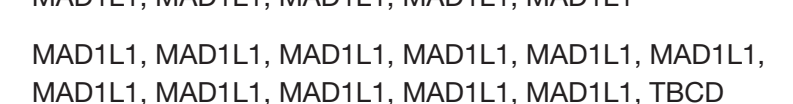 & 5.482318 & 1.24116E-1 \\
\hline o:0010948 & $\begin{array}{l}\text { logical } \\
\text { coss }\end{array}$ & Negative regulation of cell ycyle process & 3 & 11 & 226 & 45,240 & 46 & 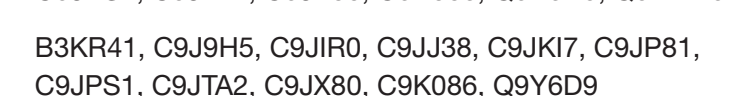 & 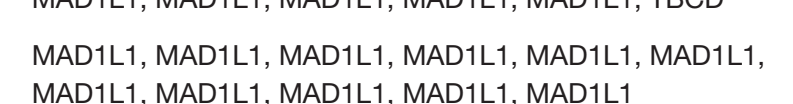 & 5.581002 & 1.20706E-1. \\
\hline o:0010965 & $\begin{array}{l}\text { bogical } \\
\text { cosss }\end{array}$ & Regulation of mitotic sister chromatid separatic & 5 & 11 & 80 & 45,240 & & 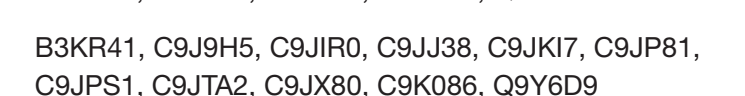 & 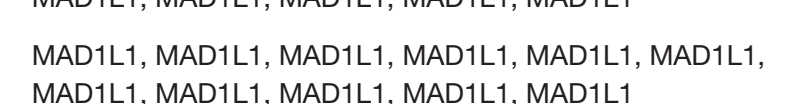 & 7.079253 & $1.5405 E-18$ \\
\hline :0:022402 & $\begin{array}{l}\text { logical } \\
\text { coss }\end{array}$ & Cell yycle procoess & ${ }^{3}$ & 11 & 1,2784 & 45,240 & 46 & 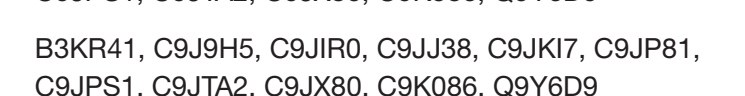 & 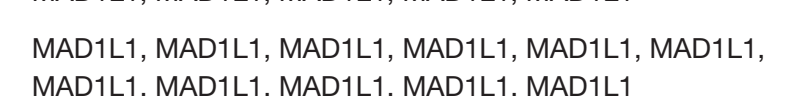 & 3.081509 & $6.23166 E-0.0$ \\
\hline :0: 0030071 & $\begin{array}{l}\text { coical } \\
\text { coss }\end{array}$ & $\begin{array}{l}\text { Regulation } \mathrm{c} \\
\text { transtion }\end{array}$ & 7 & 11 & 76 & 45,240 & & 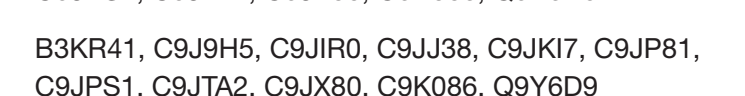 & 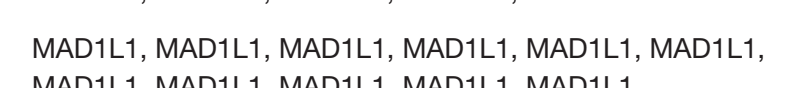 & 7.153253 & $9.65074-1$ \\
\hline o: 0031577 & $\begin{array}{l}\text { blogical } \\
\text { coss }\end{array}$ & Spindle checkpoint & 3 & 11 & 50 & 45,240 & 46 & 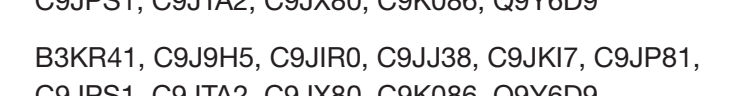 & 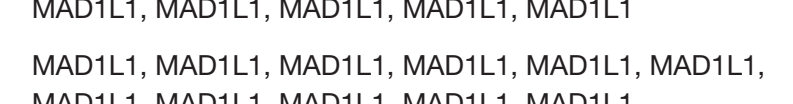 & 7.757325 & 8.97641E-2 \\
\hline :0: 0033043 & togical & Regulation of organelle organization & 2 & 12 & 854 & 45,240 & 46 & 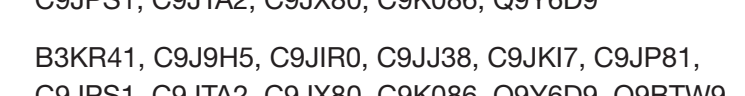 & 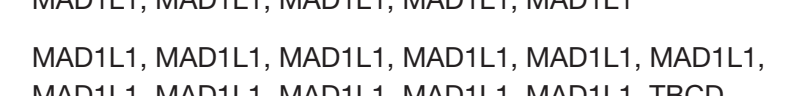 & 3.78662 & $7.71321 E-0.0$ \\
\hline o:0033044 & togical & Regulation of chromosome organization & 2 & 11 & 239 & 45,240 & 46 & 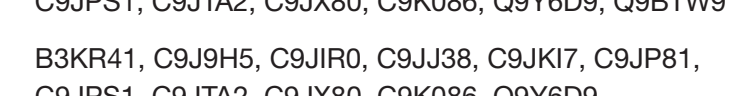 & 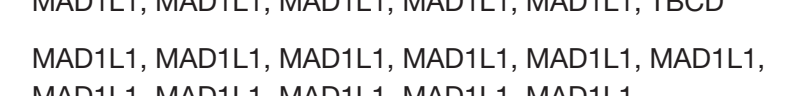 & 5.500314 & $2.01867 E-13$ \\
\hline i: 0033045 & Iogical & gulation of sister chromatids segregation & 4 & 11 & 91 & 45,240 & 46 & 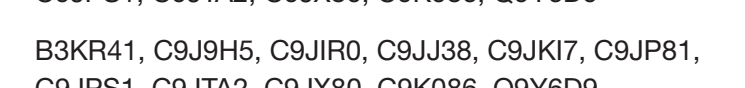 & 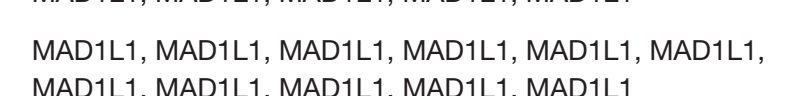 & 6.893386 & $6.4978 E-18$ \\
\hline :0:0033046 & $\begin{array}{l}\text { sogical } \\
\text { cosss }\end{array}$ & Negative regulation of sister chromatid segregation & 7 & 11 & 47 & 45,240 & 46 & 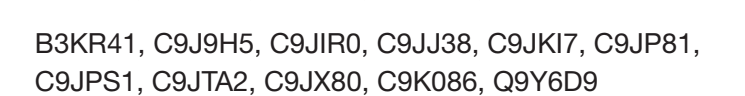 & 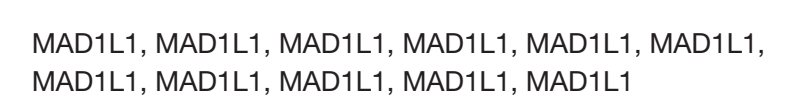 & 7.846592 & 4.66045E-2 \\
\hline o: 0033047 & $\begin{array}{c}\text { Biological } \\
\text { procoss }\end{array}$ & Regulation of mitotic sister chromatid segregation & 5 & 11 & 80 & 45,240 & ${ }_{46}$ & 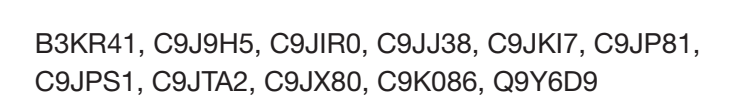 & 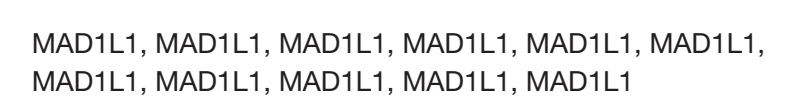 & 7.079253 & 1.54055-18 \\
\hline :0: 0033048 & $\begin{array}{c}\text { Biological } \\
\text { procoss }\end{array}$ & $\begin{array}{l}\text { Negative regulation of mitotic sister chromatid } \\
\text { segreagiton }\end{array}$ & 8 & 11 & 45 & 45,240 & 46 & 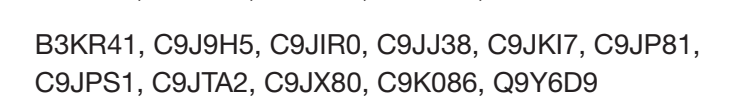 & 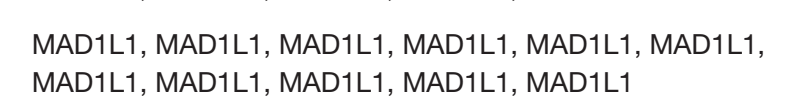 & 7.909328 & 3.49706E-2 \\
\hline 60:0045786 & $\begin{array}{c}\text { Biological } \\
\text { procoss }\end{array}$ & Negative regulation of cell cycle & 3 & 11 & 481 & 45,240 & 46 & 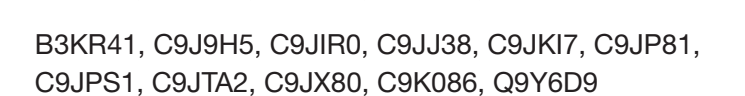 & 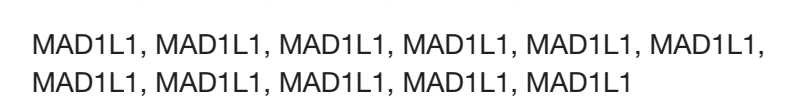 & 4.491288 & 3.49572E-1 \\
\hline 60:0045839 & Biological & Negative regulation of mitotic nuclear division & 7 & 11 & 53 & 45,240 & & 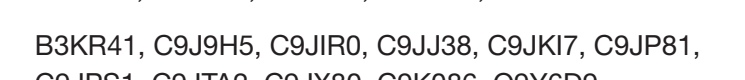 & МАDLL, MADIL1, MADDL1, MADIL1, MADLL, MADLL, & 7.673261 & 1.66166-2 \\
\hline 60: 0458541 & $\begin{array}{c}\text { Biological } \\
\text { procoss }\end{array}$ & $\begin{array}{l}\text { Negative regulation of mitotic metaphase//anap } \\
\text { transtito }\end{array}$ & 9 & 11 & 45 & 45,240 & 46 & 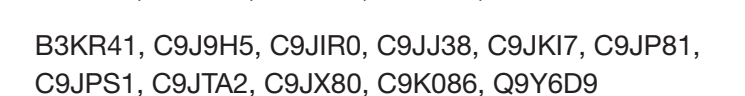 & 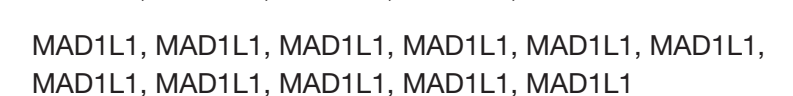 & 7.909328 & 3.49706E-2 \\
\hline 60:0045930 & $\begin{array}{c}\text { Biological } \\
\text { procoss }\end{array}$ & Negative reguation of nitoticic cell ycyle & 3 & 11 & 204 & 4,240 & 46 & 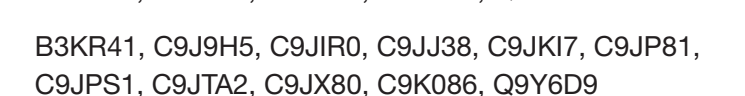 & 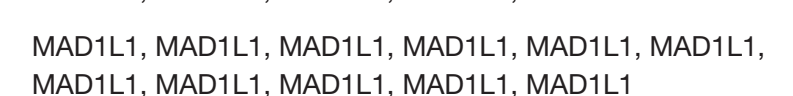 & 5.728756 & 4.016766E-1. \\
\hline 60: 0445523 & $\begin{array}{l}\text { Bilogical } \\
\text { procesas }\end{array}$ & Negative regulation of celluar r rocoess & 3 & 18 & $4,555 \quad 4$ & 45,240 & & 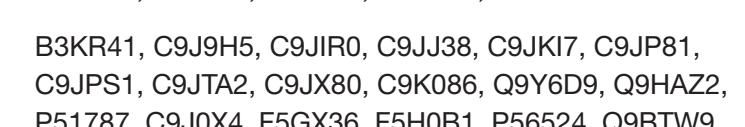 & 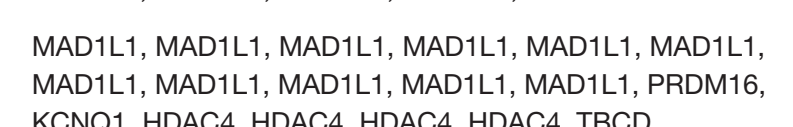 & 1.958439 & 2.17828E-0. \\
\hline :0051128 & $\begin{array}{c}\text { Biological } \\
\text { procoss }\end{array}$ & Regulation of celluar com & ${ }^{2}$ & 12 & .006 & 45,240 & 46 & 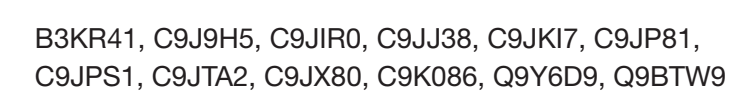 & 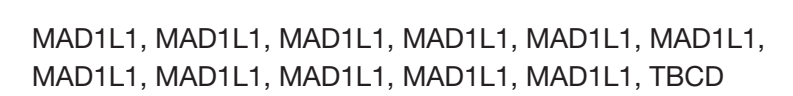 & 2.566006 & 5.28453 \\
\hline 60:0051129 & $\begin{array}{l}\text { Biological } \\
\text { procoss }\end{array}$ & $\begin{array}{l}\text { Negative regulation of celluar component } \\
\text { organination }\end{array}$ & ${ }^{4}$ & 12 & 524 & 45,240 & 46 & 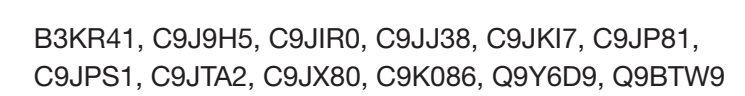 & 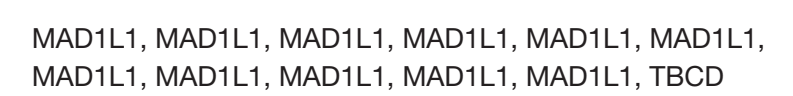 & 4.493289 & 3.19493E-1 \\
\hline 60:0051726 & $\begin{array}{c}\text { Biological } \\
\text { procoss }\end{array}$ & Regulation of cell cycle & ${ }^{2}$ & 11 & 966 & 45,240 & 46 & 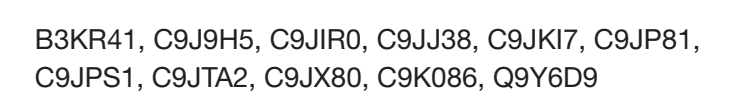 & 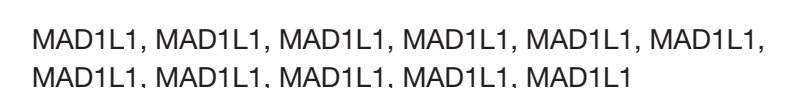 & 3.485502 & 4.03765E-07 20.7 \\
\hline 60:0051783 & $\begin{array}{l}\text { Biological } \\
\text { procoss }\end{array}$ & Regulation of nuclear division & ${ }^{2}$ & 11 & 186 & 45,240 & ${ }^{46}$ & 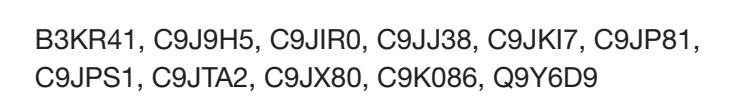 & 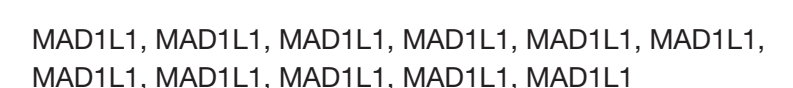 & 5.662022 & 1.49082E-1. \\
\hline 60:0051784 & $\begin{array}{l}\text { Biological } \\
\text { procoss }\end{array}$ & Negative regulation of nuclear division & 5 & 11 & 71 & 45,240 & 46 & 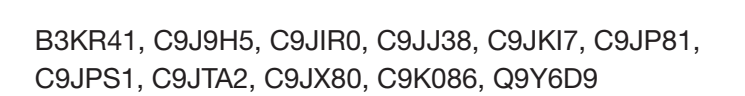 & $\begin{array}{l}\text { M.1.11, } \\
\text { M. }\end{array}$ & 7.251434 & 5.05177 \\
\hline 60:0051983 & $\begin{array}{l}\text { Biological } \\
\text { procoss }\end{array}$ & Regulation of or & 2 & 11 & 103 & 45,240 & ${ }^{46}$ & 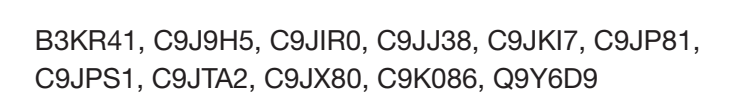 & $\begin{array}{l}\text { M.1.11, } \\
\text { M. }\end{array}$ & 6.71468 & 2.42944E-17 20 \\
\hline 60:0051985 & $\begin{array}{c}\text { Biological } \\
\text { procoss }\end{array}$ & Negative rec & ${ }^{4}$ & 11 & 47 & 45,240 & 46 & 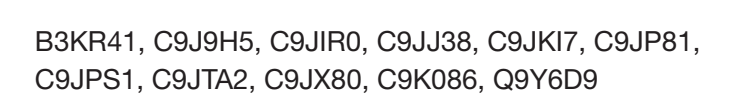 & 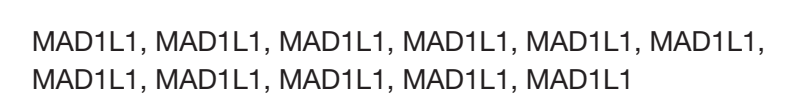 & 7.846592 & 4.66045E-21 \\
\hline 60:0071173 & $\begin{array}{c}\text { Biological } \\
\text { procoss }\end{array}$ & Spindle assembly checkpoint & ${ }^{3}$ & 11 & 45 & 45,240 & 46 & 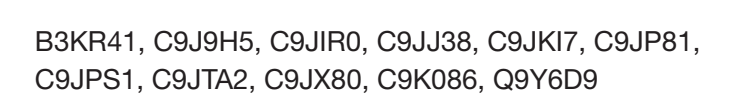 & 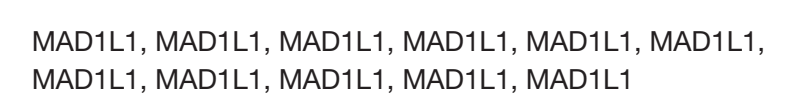 & 7.909328 & $3.49706 \mathrm{E}-2$ \\
\hline 60:0071174 & $\begin{array}{l}\text { Biological } \\
\text { pricoss }\end{array}$ & Mitotic spindle checkpoint & 11 & 11 & 45 & 45,240 & 46 & 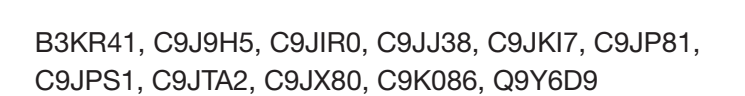 & 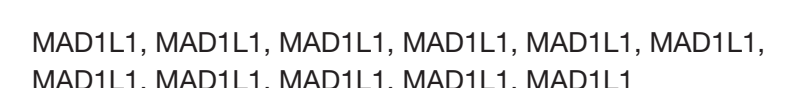 & 7.909328 & 3.499706E-21 \\
\hline 60:1901987 & $\begin{array}{l}\text { Biological } \\
\text { procoss }\end{array}$ & Regulation of cell cycle pl & ${ }^{2}$ & 11 & 237 & 45,240 & 46 & 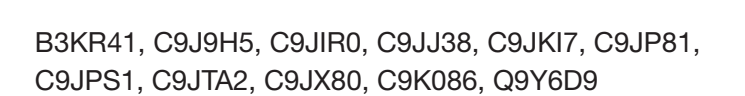 & 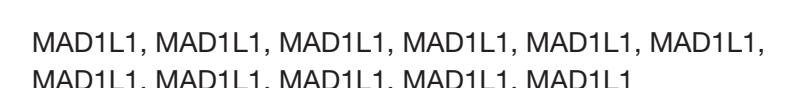 & 5.512438 & $1.9028 E-13$ \\
\hline 60:1901988 & $\begin{array}{c}\text { Biological } \\
\text { pricoss }\end{array}$ & Negative regulation of cell o, & 3 & 11 & 160 & 45,240 & 46 & 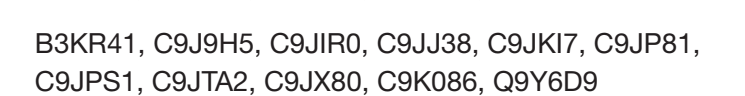 & 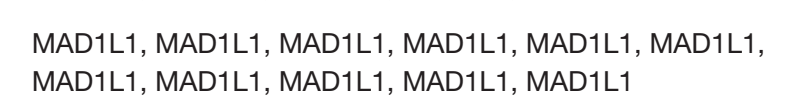 & 6.079253 & 3.13253E-1.1. \\
\hline 60:1901990 & $\begin{array}{l}\text { Biological } \\
\text { procoss }\end{array}$ & guation of mitotic cell ycycle phase transtion & 3 & 11 & 234 & 45,240 & 46 & 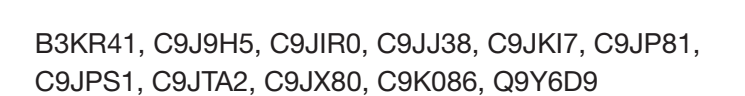 & 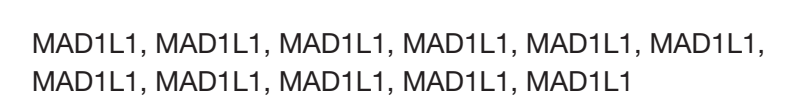 & 5.530816 & .171474 \\
\hline 60:1901991 & $\begin{array}{l}\text { Biological } \\
\text { procoss }\end{array}$ & $\underset{\substack{\text { Negative regulat } \\
\text { transtion }}}{ }$ & ${ }^{5}$ & 11 & 157 & 45,240 & 46 & 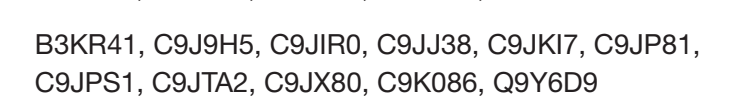 & 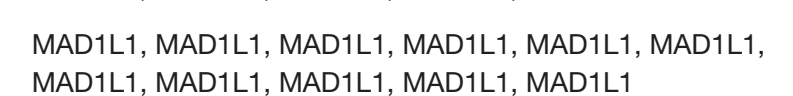 & 6.10656 & 2.652266-1. \\
\hline 60:1902099 & $\begin{array}{c}\text { Biological } \\
\text { procoss }\end{array}$ & $\begin{array}{l}\text { Regulation o } \\
\text { cycyle }\end{array}$ & 4 & 11 & 76 & 45,240 & 46 & 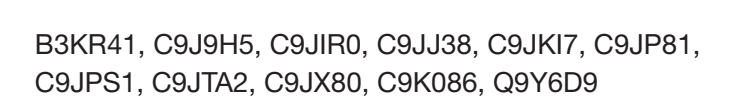 & 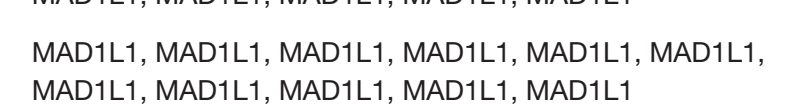 & 7.153253 & $9.65074=-1$. \\
\hline 60:1902100 & $\begin{array}{c}\text { Biological } \\
\text { procoss }\end{array}$ & $\begin{array}{l}\text { Negative regulation of metar } \\
\text { transition of of cell cycle }\end{array}$ & ${ }^{4}$ & 11 & 45 & 45,240 & 46 & 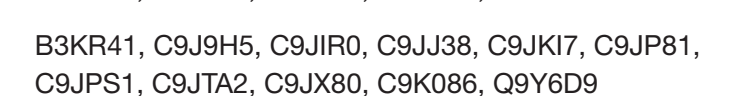 & 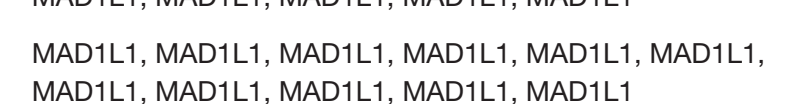 & 7.909328 & 3.499706E-21 \\
\hline G0:1903047 & $\begin{array}{c}\text { Biological } \\
\text { procoss }\end{array}$ & Mitotic cell cycle process & 4 & 11 & 726 & 45,240 & 46 & 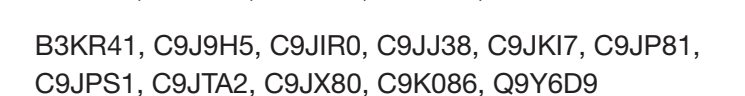 & 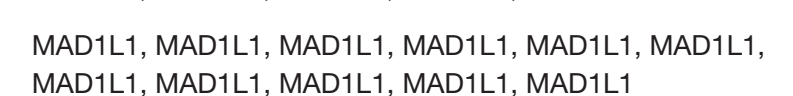 & 3.897355 & $2.31135 E-08$ \\
\hline 60:2000816 & $\begin{array}{c}\text { Biological } \\
\text { pricoss }\end{array}$ & $\begin{array}{l}\text { Negative regulation of } m \\
\text { separtion }\end{array}$ & 8 & 11 & 45 & 45,240 & 46 & 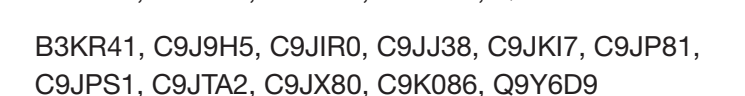 & 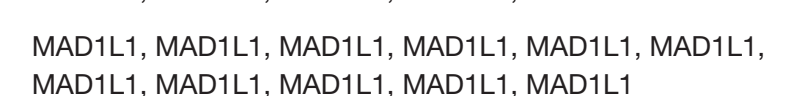 & 7.909328 & $3.497006-21$ \\
\hline G0:2001251 & $\begin{array}{c}\text { Biological } \\
\text { pricoss }\end{array}$ & Negative regulation of chromosome organization & 5 & 11 & 99 & 45,240 & 46 & 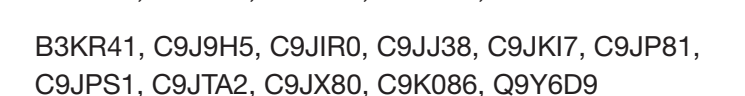 & 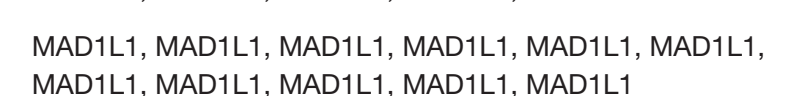 & 6.777824 & $1.62527-17$ \\
\hline 60:001529 & 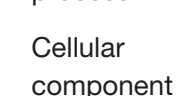 & Actin y yrosteletion & 4 & 8 & 741 & 45,240 & 46 & 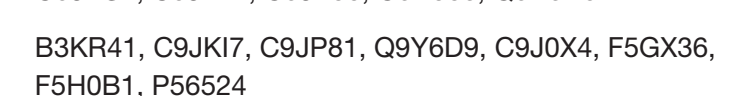 & $\begin{array}{l}\text { MADIL1, MADIL1, MAD } \\
\text { MDC, }\end{array}$ & 3.40842 & $7.07259 E-05$ \\
\hline 60: 0043467 & $\begin{array}{c}\text { Biological } \\
\text { procoss }\end{array}$ & $\begin{array}{l}\text { Regulation of } \\
\text { and enery }\end{array}$ & 3 & 5 & 71 & 45,240 & 46 & 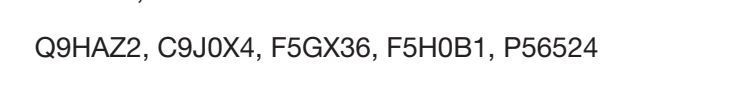 & PRDM16, HDAC4, HDAC4, HDAC4, HDAC4 & 6.111993 & 1..58738E-06 2 - \\
\hline 60:0003924 & $\begin{array}{l}\text { Molecular } \\
\text { funcition }\end{array}$ & Gipase activity & 1 & 7 & 456 & 45,240 & 46 & 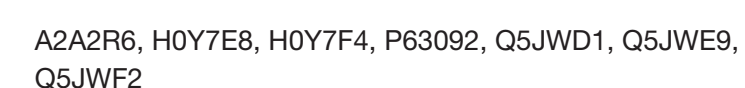 & GNAS, GNAS, GNAS, GNAS, GNAS, GNAS, GNAS & 3.916214 & 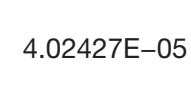 \\
\hline 60:0031683 & $\begin{array}{c}\text { Molecular } \\
\text { tuction }\end{array}$ & G-prototin beta & 2 & 7 & 53 & 45,240 & 46 & 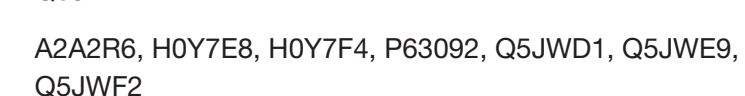 & GNAS, GNAS, GNAS, GNAS, GNAS, GNAS, GNAS & 7.021184 & 2.43723E-11 \\
\hline $0: 045667$ & $\begin{array}{l}\text { Biological } \\
\text { process }\end{array}$ & Regulation of osteoblast difiterentiation & 3 & 5 & 157 & 45,240 & 46 & 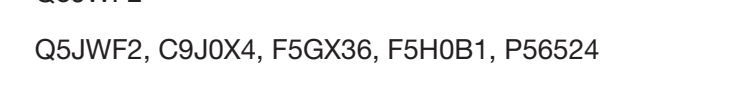 & GNAS, HDAC4, HDAC4, HDAC4, HDAC4 & 4.960057 & 5.56829E-0. \\
\hline i: 00080016 & $\begin{array}{l}\text { Biological } \\
\text { oryocess }\end{array}$ & Regulation of heart contracacic & 2 & 5 & 178 & 45,240 & 46 & 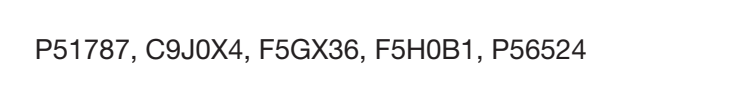 & KCNO1, HDAC4, HDACC4, HDAC4, HC & 4.787944 & 9.84102E-0. \\
\hline i: 0002076 & $\begin{array}{l}\text { Biological } \\
\text { ortocess }\end{array}$ & Osteoblast development & 6 & 4 & 33 & 45,240 & 46 & 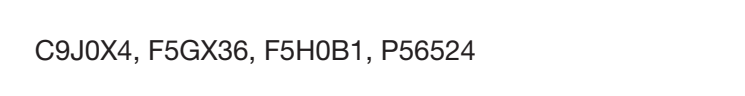 & HACC, HDAC4, & 6.897355 & 5.03412E-0.0 \\
\hline i: 000642 & Biological & Guation of of strateded $\mathrm{m}$ & 2 & 4 & 63 & 45,240 & 46 & 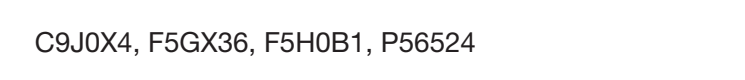 & HAAC4, HDAC4, HDAC4, HDAC4 & 5.964469 & 5.28453E-0. \\
\hline 10:0010882 & $\begin{array}{l}\text { Biological } \\
\text { orycoss }\end{array}$ & $\begin{array}{l}\text { Regulation of cardiac } \\
\text { calcimm ion sionalina }\end{array}$ & 5 & 4 & 25 & 45,240 & 46 & 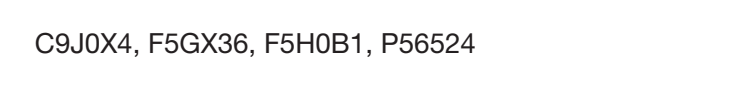 & HAAC4, HDAC4, HAAC4, HDAC4 & 7.297893 & 1.65414E-0. 0 \\
\hline 10:0055117 & $\begin{array}{l}\text { Biological } \\
\text { arrocess }\end{array}$ & Regulation of carciac musc & 3 & 4 & 52 & 45,240 & 46 & 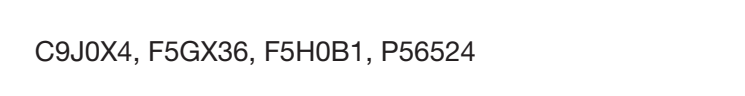 & IAC4, HAAC4, & 6.24131 & . $704388-0$. \\
\hline i: : 0014854 & Biological & ponse to inactivity & 1 & 4 & 10 & 45,240 & 46 & 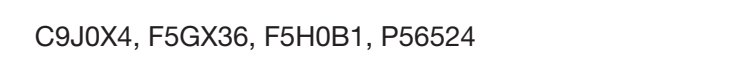 & HDAC4, HDAC4, HAAC4, HDAC4 & 8.619821 & 3.27042E-0: \\
\hline i: :0014870 & $\begin{array}{l}\text { Biological } \\
\text { seroces }\end{array}$ & sponset to muscle inac & 1 & 4 & 7 & 45,240 & 46 & C900X4, F5G ₹36, F5H0B1, Р56524 & HDAC4, HAAC4, HDAC4, HAAC4 & 9.134394 & 6.0331E-09 \\
\hline i: :0014874 & $\begin{array}{l}\text { Biological } \\
\text { Nerecesa }\end{array}$ & $\begin{array}{l}\text { Response to stimulus i } \\
\text { muscle }\end{array}$ & 3 & 4 & 11 & 45,240 & 46 & 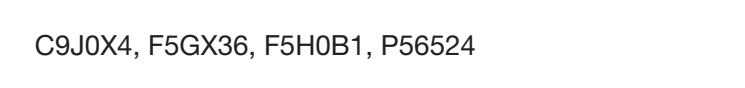 & HAAC4, HAAC4, HDAC4, HAAC4 & 8.482318 & 5.02378E-08 \\
\hline 60:0014877 & $\begin{array}{l}\text { Biological } \\
\text { Nerecesa }\end{array}$ & $\begin{array}{l}\text { Response to } m u \\
\text { sef muscla }\end{array}$ & 5 & 4 & 7 & 45,240 & 46 & 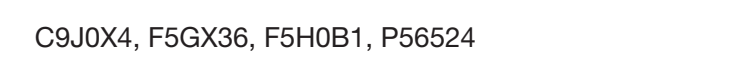 & HAAC4, HAAC4, HDAC4, HAAC4 & 9.1343944 & 6.030311-09 \\
\hline 60: 00148994 & $\begin{array}{l}\text { Biological } \\
\text { Biogical }\end{array}$ & 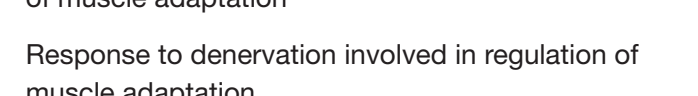 & 5 & 4 & 7 & 45,240 & 46 & 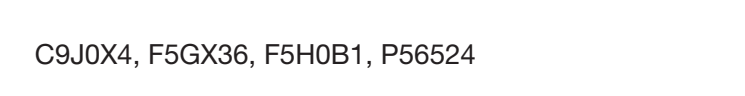 & HAAC4, HDAC4, HDAC4, HDAC4 & 9.134394 & 6.00311-09 \\
\hline :0:0043502 & $\begin{array}{l}\text { Miological } \\
\text { Biogical }\end{array}$ & Regulation of muscle adapatation & 3 & 4 & 44 & 45,240 & 46 & 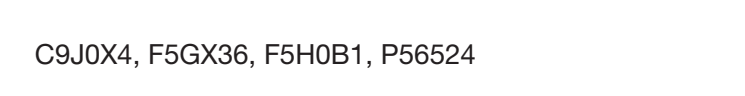 & HAAC4, HDACG, HDACG, HDACC4 & 6.482318 & 1.42711E-05 \\
\hline i: 0031672 & Celluar & A band & 7 & 4 & 41 & 45,240 & 46 & 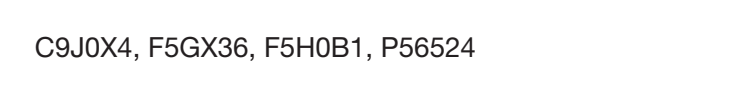 & DACC4, HDAC4, HDAC4, HDAC4 & 6.584197 & 1.10087E-05 \\
\hline i: :0019213 & lecular & Deacetylyse & 1 & 4 & 73 & 45,240 & 46 & C900X4, F5G Х36, F F50В1, Р56524 & HAAC4, HDAC4, HDAC4, HDAC4 & 5.751925 & $8.98652 E-05$ \\
\hline :0:003558 & . & Protein deacetyly & 1 & 4 & 56 & 45,240 & 46 & 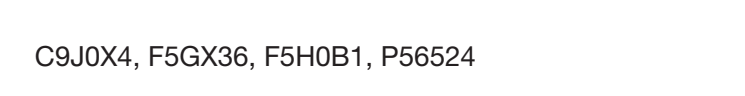 & HAAC4, HDAC4, HDAC4, HDAC4 & 6.1343994 & 3.5536E-05 \\
\hline i: : 0042641 & Celluar & Actomyosin & 6 & 4 & 67 & 45,240 & 46 & 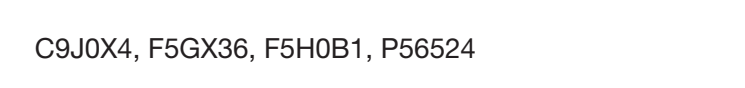 & DAC4, HDAC4, HDAC4, HDAC4 & 5.87566 & $6.57755 E-05$ \\
\hline o: 0445668 & Biological & legative & 5 & 4 & 57 & 45,240 & 46 & 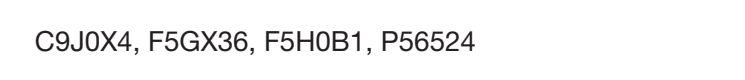 & HDAC4, HDAC4, HDAC4, HDAC4 & 6.108859 & 3.76518E-05 \\
\hline o: 0006110 & Biological & Reguation of & 7 & 4 & 25 & 45,240 & 46 & 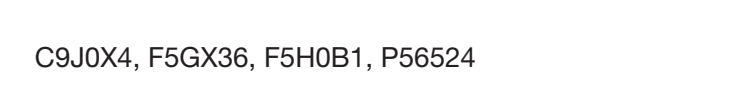 & HACC, HDAC4, & 7.297893 & $1.65414 E-06$ \\
\hline o: 0009118 & Biological & Regulation & 4 & 4 & 30 & 45,240 & 46 & 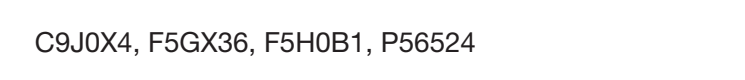 & IDAC4, HDAC. & 7.034859 & 3.44042E- -06 \\
\hline i: :0010677 & $\begin{array}{l}\text { Bilogical } \\
\text { arrocess }\end{array}$ & vivereg & 6 & 4 & 36 & 45,240 & 46 & H.88, P56524 & DAC4, HAAC4, & 6.771824 & 812424E-0 \\
\hline 0:0043470 & $\begin{array}{l}\text { Biological } \\
\text { arrocess }\end{array}$ & Regulation of & 3 & 4 & 37 & 45,240 & 46 & P56524 & & 6.732296 & 7.68077-06 \\
\hline 0:0045820 & Biological & procoess & 12 & 4 & 8 & 45,240 & ${ }^{46}$ & C9J0X4, F5 & & 8.941749 & 14254E-08 \\
\hline 6:00459912 & gical & & 4 & 4 & 40 & 45,240 & ${ }^{46}$ & 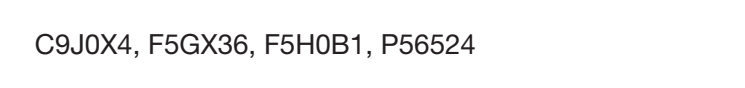 & & 6.619821 & $002024-055$ \\
\hline o: 0045978 & gical & & 7 & ${ }^{4}$ & 12 & 45,240 & 46 & 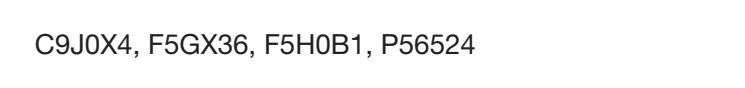 & & 8.356787 & 7.06904E \\
\hline 0:0045980 & & Negative regulatic & 8 & 4 & 62 & 45.240 & 46 & P56524 & & 5.987553 & 88282E-05 \\
\hline 0:0051193 & & ic rocoess & 3 & 4 & 39 & 45,240 & 46 & 81, P56524 & & 6.656347 & 48009-06 \\
\hline 0:0051195 & & Negative regu & 6 & 4 & 8 & 45,240 & 46 & 81, F56524 & & 8.94749 & 42554 \\
\hline 0:0051196 & & Regulation o & 3 & 4 & 39 & 45,240 & 46 & 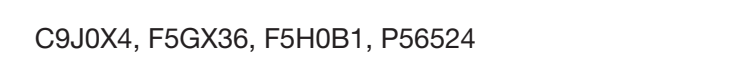 & & 6.656347 & $24009-066$ \\
\hline fo: 0051198 & $\begin{array}{l}\text { Bilogical } \\
\text { Bingeal }\end{array}$ & Negative reg & 7 & 4 & 8 & 45,240 & 46 & C9010X4, F5XX36, F550B1, F56524 & & 8.94749 & 1254E \\
\hline 6:1900543 & $\begin{array}{l}\text { Biological } \\
\text { Bincical }\end{array}$ & & 9 & 4 & 60 & 45,240 & ${ }^{46}$ & C950X4, F5XX36, F F5HOB1, F56524 & & 6.034859 & 10666-05: \\
\hline 10:1903578 & Biological & metabolic process & 5 & 4 & ${ }_{30}$ & 45,240 & 46 & C950X4, F5XX36, F550B1, F56524 & & 7.0348599 & .44042E-06 \\
\hline 0:19003579 & $\begin{array}{l}\text { Biological } \\
\text { Biogec }\end{array}$ & Negative regulation of $A$ & 11 & 4 & 12 & 45,240 & 46 & 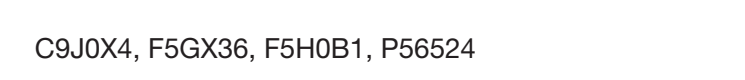 & DAC4, HDAC4, HDAC4, HAAC4 & 8.356787 72. & 7.06904E-08 \\
\hline 60:0010830 & Biological & Regulation of myotube difiterentiation & 3 & 4 & 50 & 45,240 & 46 & 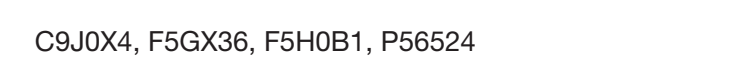 & DAC4, HDAC4 & 6.227893 & 2.33836E-05 \\
\hline 60:0048742 & $\begin{array}{l}\text { logical } \\
\text { cess }\end{array}$ & guation of stseletal muscle fiber de & 5 & 3 & 13 & 45,240 & 46 & 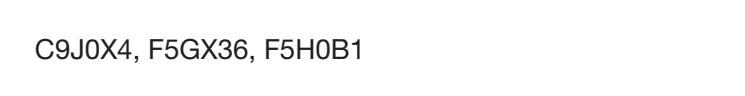 & HDAC4, HDAC4, HDAC4 & 7.826272 & 3.04774E=-0. \\
\hline
\end{tabular}




\begin{tabular}{|c|c|c|c|c|c|c|c|c|c|}
\hline \#Term & Database & ID & $\begin{array}{l}\text { Input } \\
\text { number }\end{array}$ & $\begin{array}{l}\text { Background } \\
\text { number }\end{array}$ & P value & Corrected & $P$ value & Input & Hyperlink \\
\hline Vibrio cholerae infection & KEGG PATHWAY & hsa05110 & 2 & 50 & 0.006229 & 0.308577 & 0.510637 & ENSG00000087460, ENSG00000053918 & http://www.genome.jp/kegg-bin/show_pathway?hsa05110/hsa:2778\%09red/hsa:3784\%09red \\
\hline Gastric acid secretion & KEGG PATHWAY & hsa04971 & 2 & 74 & 0.012932 & 0.308577 & 0.510637 & ENSG00000087460, ENSG00000053918 & http://www.genome.jp/kegg-bin/show_pathway?hsa04971/hsa:2778\%09red/hsa:3784\%09red \\
\hline Pancreatic secretion & KEGG PATHWAY & hsa04972 & 2 & 96 & 0.020893 & 0.308577 & 0.510637 & ENSG00000087460, ENSG00000053918 & http://www.genome.jp/kegg-bin/show_pathway?hsa04972/hsa:2778\%09red/hsa:3784\%09red \\
\hline Adrenergic signaling in cardiomyocytes & KEGG PATHWAY & hsa04261 & 2 & 151 & 0.047242 & 0.308577 & 0.510637 & ENSG00000087460, ENSG00000053918 & http://www.genome.jp/kegg-bin/show_pathway?hsa04261/hsa:2778\%09red/hsa:3784\%09red \\
\hline Alcoholism & KEGG PATHWAY & hsa05034 & 2 & 180 & 0.064213 & 0.308577 & 0.510637 & ENSG00000087460, ENSG00000068024 & http://www.genome.jp/kegg-bin/show_pathway?hsa05034/hsa:9759\%09red/hsa:2778\%09red \\
\hline Viral carcinogenesis & KEGG PATHWAY & hsa05203 & 2 & 207 & 0.08156 & 0.308577 & 0.510637 & ENSG00000002822, ENSG00000068024 & http://www.genome.jp/kegg-bin/show_pathway?hsa05203/hsa:9759\%09red/hsa:8379\%09red \\
\hline Type I diabetes mellitus & KEGG PATHWAY & hsa04940 & 1 & 42 & 0.093054 & 0.308577 & 0.510637 & ENSG00000155093 & http://www.genome.jp/kegg-bin/show_pathway?hsa04940/hsa:5799\%09red \\
\hline $\begin{array}{l}\text { Endocrine and other factor-regulated } \\
\text { calcium reabsorption }\end{array}$ & KEGG PATHWAY & hsa04961 & 1 & 47 & 0.103306 & 0.308577 & 0.510637 & ENSG00000087460 & http://www.genome.jp/kegg-bin/show_pathway?hsa04961/hsa:2778\%09red \\
\hline Cocaine addiction & KEGG PATHWAY & hsa05030 & 1 & 49 & 0.107375 & 0.308577 & 0.510637 & ENSG00000087460 & http://www.genome.jp/kegg-bin/show_pathway?hsa05030/hsa:2778\%09red \\
\hline Ovarian steroidogenesis & KEGG PATHWAY & hsa04913 & 1 & 52 & 0.113444 & 0.308577 & 0.510637 & ENSG00000087460 & http://www.genome.jp/kegg-bin/show_pathway?hsa04913/hsa:2778\%09red \\
\hline Regulation of lipolysis in adipocytes & KEGG PATHWAY & hsa04923 & 1 & 58 & 0.12546 & 0.308577 & 0.510637 & ENSG00000087460 & http://www.genome.jp/kegg-bin/show_pathway?hsa04923/hsa:2778\%09red \\
\hline MicroRNAs in cancer & KEGG PATHWAY & hsa05206 & 2 & 273 & 0.128856 & 0.308577 & 0.510637 & ENSG00000068024, ENSG00000168477 & http://www.genome.jp/kegg-bin/show_pathway?hsa05206/hsa:9759\%09red/hsa:7148\%09red \\
\hline Long-term depression & KEGG PATHWAY & hsa04730 & 1 & 61 & 0.131408 & 0.308577 & 0.510637 & ENSG00000087460 & http://www.genome.jp/kegg-bin/show_pathway?hsa04730/hsa:2778\%09red \\
\hline Renin secretion & KEGG PATHWAY & hsa04924 & 1 & 64 & 0.137317 & 0.308577 & 0.510637 & ENSG00000087460 & http://www.genome.jp/kegg-bin/show_pathway?hsa04924/hsa:2778\%09red \\
\hline Thyroid hormone synthesis & KEGG PATHWAY & hsa04918 & 1 & 71 & 0.150949 & 0.308577 & 0.510637 & ENSG00000087460 & http://www.genome.jp/kegg-bin/show_pathway?hsa04918/hsa:2778\%09red \\
\hline Aldosterone synthesis and secretion & KEGG PATHWAY & hsa04925 & 1 & 80 & 0.168167 & 0.308577 & 0.510637 & ENSG00000087460 & http://www.genome.jp/kegg-bin/show_pathway?hsa04925/hsa:2778\%09red \\
\hline ECM-receptor interaction & KEGG PATHWAY & hsa04512 & 1 & 83 & 0.173829 & 0.308577 & 0.510637 & ENSG00000168477 & http://www.genome.jp/kegg-bin/show_pathway?hsa04512/hsa:7148\%09red \\
\hline Insulin secretion & KEGG PATHWAY & hsa04911 & 1 & 87 & 0.18132 & 0.308577 & 0.510637 & ENSG00000087460 & http://www.genome.jp/kegg-bin/show_pathway?hsa04911/hsa:2778\%09red \\
\hline Gap junction & KEGG PATHWAY & hsa04540 & 1 & 88 & 0.183182 & 0.308577 & 0.510637 & ENSG00000087460 & http://www.genome.jp/kegg-bin/show_pathway?hsa04540/hsa:2778\%09red \\
\hline Salivary secretion & KEGG PATHWAY & hsa04970 & 1 & 90 & 0.186894 & 0.308577 & 0.510637 & ENSG00000087460 & http://www.genome.jp/kegg-bin/show_pathway?hsa04970/hsa:2778\%09red \\
\hline Dilated cardiomyopathy & KEGG PATHWAY & hsa05414 & 1 & 90 & 0.186894 & 0.308577 & 0.510637 & ENSG00000087460 & http://www.genome.jp/kegg-bin/show_pathway?hsa05414/hsa:2778\%09red \\
\hline Protein digestion and absorption & KEGG PATHWAY & hsa04974 & 1 & 90 & 0.186894 & 0.308577 & 0.510637 & ENSG00000053918 & http://www.genome.jp/kegg-bin/show_pathway?hsa04974/hsa:3784\%09red \\
\hline Morphine addiction & KEGG PATHWAY & hsa05032 & 1 & 91 & 0.188744 & 0.308577 & 0.510637 & ENSG00000087460 & http://www.genome.jp/kegg-bin/show_pathway?hsa05032/hsa:2778\%09red \\
\hline GnRH signaling pathway & KEGG PATHWAY & hsa04912 & 1 & 92 & 0.19059 & 0.308577 & 0.510637 & ENSG00000087460 & http://www.genome.jp/kegg-bin/show_pathway?hsa04912/hsa:2778\%09red \\
\hline Circadian entrainment & KEGG PATHWAY & hsa04713 & 1 & 95 & 0.196102 & 0.308577 & 0.510637 & ENSG00000087460 & http://www.genome.jp/kegg-bin/show_pathway?hsa04713/hsa:2778\%09red \\
\hline ProgesteronE-mediated oocyte maturation & KEGG PATHWAY & hsa04914 & 1 & 97 & 0.199757 & 0.308577 & 0.510637 & ENSG00000002822 & http://www.genome.jp/kegg-bin/show_pathway?hsa04914/hsa:8379\%09red \\
\hline Endocrine resistance & KEGG PATHWAY & hsa01522 & 1 & 99 & 0.203395 & 0.308577 & 0.510637 & ENSG00000087460 & http://www.genome.jp/kegg-bin/show_pathway?hsa01522/hsa:2778\%09red \\
\hline Melanogenesis & KEGG PATHWAY & hsa04916 & 1 & 100 & 0.205207 & 0.308577 & 0.510637 & ENSG00000087460 & http://www.genome.jp/kegg-bin/show_pathway?hsa04916/hsa:2778\%09red \\
\hline Amoebiasis & KEGG PATHWAY & hsa05146 & 1 & 100 & 0.205207 & 0.308577 & 0.510637 & ENSG00000087460 & http://www.genome.jp/kegg-bin/show_pathway?hsa05146/hsa:2778\%09red \\
\hline $\begin{array}{l}\text { Inflammatory mediator regulation of TRP } \\
\text { channels }\end{array}$ & KEGG PATHWAY & hsa04750 & 1 & 101 & 0.207016 & 0.308577 & 0.510637 & ENSG00000087460 & http://www.genome.jp/kegg-bin/show_pathway?hsa04750/hsa:2778\%09red \\
\hline Chagas disease (American trypanosomiasis) & KEGG PATHWAY & hsa05142 & 1 & 106 & 0.216 & 0.308577 & 0.510637 & ENSG00000087460 & http://www.genome.jp/kegg-bin/show_pathway?hsa05142/hsa:2778\%09red \\
\hline Cholinergic synapse & KEGG PATHWAY & hsa04725 & 1 & 113 & 0.228409 & 0.308577 & 0.510637 & ENSG00000053918 & http://www.genome.jp/kegg-bin/show_pathway?hsa04725/hsa:3784\%09red \\
\hline Serotonergic synapse & KEGG PATHWAY & hsa04726 & 1 & 113 & 0.228409 & 0.308577 & 0.510637 & ENSG00000087460 & http://www.genome.jp/kegg-bin/show_pathway?hsa04726/hsa:2778\%09red \\
\hline Glutamatergic synapse & KEGG PATHWAY & hsa04724 & 1 & 115 & 0.231919 & 0.308577 & 0.510637 & ENSG00000087460 & http://www.genome.jp/kegg-bin/show_pathway?hsa04724/hsa:2778\%09red \\
\hline Vascular smooth muscle contraction & KEGG PATHWAY & hsa04270 & 1 & 123 & 0.245803 & 0.308577 & 0.510637 & ENSG00000087460 & http://www.genome.jp/kegg-bin/show_pathway?hsa04270/hsa:2778\%09red \\
\hline Cell cycle & KEGG PATHWAY & hsa04110 & 1 & 124 & 0.247521 & 0.308577 & 0.510637 & ENSG00000002822 & http://www.genome.jp/kegg-bin/show_pathway?hsa04110/hsa:8379\%09red \\
\hline Platelet activation & KEGG PATHWAY & hsa04611 & 1 & 125 & 0.249235 & 0.308577 & 0.510637 & ENSG00000087460 & http://www.genome.jp/kegg-bin/show_pathway?hsa04611/hsa:2778\%09red \\
\hline Dopaminergic synapse & KEGG PATHWAY & hsa04728 & 1 & 129 & 0.256053 & 0.309646 & 0.509135 & ENSG00000087460 & http://www.genome.jp/kegg-bin/show_pathway?hsa04728/hsa:2778\%09red \\
\hline Phospholipase D signaling pathway & KEGG PATHWAY & hsa04072 & 1 & 146 & 0.284358 & 0.336059 & 0.473584 & ENSG00000087460 & http://www.genome.jp/kegg-bin/show_pathway?hsa04072/hsa:2778\%09red \\
\hline Oxytocin signaling pathway & KEGG PATHWAY & hsa04921 & 1 & 160 & 0.306871 & 0.354606 & 0.450254 & ENSG00000087460 & http://www.genome.jp/kegg-bin/show_pathway?hsa04921/hsa:2778\%09red \\
\hline Calcium signaling pathway & KEGG PATHWAY & hsa04020 & 1 & 179 & 0.336314 & 0.380181 & 0.42001 & ENSG00000087460 & http://www.genome.jp/kegg-bin/show_pathway?hsa04020/hsa:2778\%09red \\
\hline cAMP signaling pathway & KEGG PATHWAY & hsa04024 & 1 & 201 & 0.368872 & 0.399073 & 0.398948 & ENSG00000087460 & http://www.genome.jp/kegg-bin/show_pathway?hsa04024/hsa:2778\%09red \\
\hline Epstein-Barr virus infection & KEGG PATHWAY & hsa05169 & 1 & 204 & 0.373188 & 0.399073 & 0.398948 & ENSG00000068024 & http://www.genome.jp/kegg-bin/show_pathway?hsa05169/hsa:9759\%09red \\
\hline Focal adhesion & KEGG PATHWAY & hsa04510 & 1 & 206 & 0.376049 & 0.399073 & 0.398948 & ENSG00000168477 & http://www.genome.jp/kegg-bin/show_pathway?hsa04510/hsa:7148\%09red \\
\hline Rap1 signaling pathway & KEGG PATHWAY & hsa04015 & 1 & 216 & 0.390165 & 0.405771 & 0.391719 & ENSG00000087460 & http://www.genome.jp/kegg-bin/show_pathway?hsa04015/hsa:2778\%09red \\
\hline PI3K-Akt signaling pathway & KEGG PATHWAY & hsa04151 & 1 & 343 & 0.544312 & 0.554985 & 0.255719 & ENSG00000168477 & http://www.genome.jp/kegg-bin/show_pathway?hsa04151/hsa:7148\%09red \\
\hline Pathways in cancer & KEGG PATHWAY & hsa05200 & 1 & 399 & 0.599439 & 0.599439 & 0.222255 & ENSG00000087460 & http://www.genome.jp/kegg-bin/show_pathway?hsa05200/hsa:2778\%09red \\
\hline
\end{tabular}

Statistical test method: hypergeometric test/Fisher's exact test. FDR correction method: Benjamini and Hochberg. 
Table S4 60 genes with significant hypermethylation and hypomethylation of overlap genes between B (pericarcinous tissues) vs. C (pancreatic cancer tissue) and A (blood) vs. B (pericarcinous tissues)

\begin{tabular}{|c|c|c|c|c|c|c|}
\hline Genes & Diff score & Chromosome & Position & Methylation status & $\mathrm{P}$ value (B vs. $\mathrm{C})$ & $P$ value (A vs. $B$ ) \\
\hline ZNF323 & 131.89468 & 6 & 28431998 & High-GpG & $4.16001 \mathrm{E}-07$ & $1.55395 \mathrm{E}-07$ \\
\hline$A S A H 1$ & 130.81353 & 8 & 17986262 & High-GpG & $2.01169 \mathrm{E}-07$ & $4.1218 \mathrm{E}-07$ \\
\hline FAM111A & 130.45708 & 11 & 58666572 & High-GpG & $1.21744 \mathrm{E}-05$ & 7.39343E-09 \\
\hline MAD2L1 & 129.33632 & 4 & 121207392 & High-GpG & $5.45286 \mathrm{E}-07$ & $2.1367 \mathrm{E}-07$ \\
\hline ATG12 & 127.27827 & 5 & 115205360 & High-GpG & $8.27127 \mathrm{E}-07$ & $2.26256 \mathrm{E}-07$ \\
\hline ZNF28 & 127.26429 & 19 & 58016010 & High-GpG & $1.55587 \mathrm{E}-06$ & $1.2067 \mathrm{E}-07$ \\
\hline$H A D H B$ & 125.49116 & 2 & 26320955 & High-GpG & 4.79904E-06 & $5.88478 \mathrm{E}-08$ \\
\hline PRKCG & 125.39503 & 19 & 59077027 & High-GpG & $2.97625 \mathrm{E}-05$ & $9.70126 \mathrm{E}-09$ \\
\hline PTGES2 & 124.99208 & 9 & 129930459 & High-GpG & $8.51945 \mathrm{E}-07$ & $3.7186 \mathrm{E}-07$ \\
\hline AK2 & 124.18006 & 1 & 33275020 & High-GpG & $1.48229 \mathrm{E}-07$ & $2.57668 \mathrm{E}-06$ \\
\hline MAGOHB & 123.44346 & 12 & 10657370 & High-GpG & $8.11057 \mathrm{E}-05$ & $5.57958 \mathrm{E}-09$ \\
\hline NFXL1 & 122.4017 & 4 & 47611255 & High-GpG & $1.88006 \mathrm{E}-06$ & 3.05955E-07 \\
\hline MOBKL3 & 120.93052 & 2 & 198088826 & High-GpG & $2.86446 \mathrm{E}-06$ & 2.81777E-07 \\
\hline FAM76A & 120.92863 & 1 & 27925162 & High-GpG & $1.06657 \mathrm{E}-06$ & $7.57092 \mathrm{E}-07$ \\
\hline SUPT4H1 & 119.87514 & 17 & 53784566 & High-GpG & $1.36289 \mathrm{E}-05$ & $7.55137 \mathrm{E}-08$ \\
\hline PFN4 & 118.79988 & 2 & 24199741 & High-GpG & $5.71282 \mathrm{E}-06$ & $2.30761 \mathrm{E}-07$ \\
\hline NTAN1 & 117.88967 & 16 & 15057701 & High-GpG & $1.57434 \mathrm{E}-06$ & $1.03261 \mathrm{E}-06$ \\
\hline ETNK1 & 117.59242 & 12 & 22669361 & High-GpG & 3.17717E-06 & $5.47921 \mathrm{E}-07$ \\
\hline$R A L Y$ & 117.18969 & 20 & 32046086 & High-GpG & $9.3884 \mathrm{E}-06$ & $2.03442 \mathrm{E}-07$ \\
\hline CCND1 & 116.8124 & 11 & 69164711 & High-GpG & $1.57231 \mathrm{E}-06$ & $1.32502 \mathrm{E}-06$ \\
\hline$A S A P 3$ & 116.03716 & 1 & 23683861 & High-GpG & 7.38714E-05 & 3.37139E-08 \\
\hline ERCC4 & 115.92696 & 16 & 13921604 & High-GpG & 2.69769E-07 & $9.46918 \mathrm{E}-06$ \\
\hline UBE2K & 115.73845 & 4 & 39375775 & High-GpG & 0.000128084 & 2.08286E-08 \\
\hline KIAA1324L & 115.34069 & 7 & 86526859 & High-GpG & 3.39017E-06 & $8.62402 \mathrm{E}-07$ \\
\hline$A P 1 A R$ & 115.30214 & 4 & 113372285 & High-GpG & 4.0348E-06 & 7.31079E-07 \\
\hline C1GALT1 & 114.78336 & 7 & 7188867 & High-GpG & $4.95185 \mathrm{E}-06$ & $6.71268 \mathrm{E}-07$ \\
\hline $\mathrm{NCAPH}$ & 114.77977 & 2 & 96365157 & High-GpG & $6.31399 \mathrm{E}-05$ & $5.26889 \mathrm{E}-08$ \\
\hline $\mathrm{GCSH}$ & 114.74176 & 16 & 79687498 & High-GpG & 4.30184E-07 & $7.80136 \mathrm{E}-06$ \\
\hline DHCR24 & 114.43711 & 1 & 55125751 & High-GpG & $1.87238 \mathrm{E}-05$ & $1.92263 \mathrm{E}-07$ \\
\hline HNRNPA1 & 114.07533 & 12 & 52960808 & High-GpG & 0.000139304 & $2.80869 \mathrm{E}-08$ \\
\hline GPR109A & -90.42935 & 12 & 121755189 & Low-CpG & $7.59402 \mathrm{E}-06$ & 0.000119287 \\
\hline RGPD3 & -91.08637 & 2 & 106451234 & Low-CpG & $4.72388 \mathrm{E}-05$ & $1.64841 \mathrm{E}-05$ \\
\hline C17orf98 & -92.50327 & 17 & 34251672 & Low-CpG & 0.00010681 & $5.2609 \mathrm{E}-06$ \\
\hline AP1B1 & -93.62296 & 22 & 28115355 & Low-CpG & 2.05317E-05 & $2.11484 \mathrm{E}-05$ \\
\hline DSCR8 & -93.67115 & 21 & 38415359 & Low-CpG & 0.002349546 & $1.82768 \mathrm{E}-07$ \\
\hline SNORD89 & -94.64155 & 2 & 101256138 & Low-CpG & $2.65111 \mathrm{E}-05$ & 1.29544E-05 \\
\hline MTL5 & -95.11474 & 11 & 68275537 & Low-CpG & $8.07261 \mathrm{E}-06$ & $3.81515 \mathrm{E}-05$ \\
\hline WRB & -95.16274 & 21 & 39672973 & Low-CpG & $1.04278 \mathrm{E}-05$ & $2.92101 \mathrm{E}-05$ \\
\hline NALCN & -95.55199 & 13 & 100866990 & Low-CpG & 0.000157631 & $1.76669 \mathrm{E}-06$ \\
\hline ZNF100 & -97.47202 & 19 & 21725295 & Low-CpG & 1.15163E-05 & $1.55412 \mathrm{E}-05$ \\
\hline PHACTR4 & -97.70953 & 1 & 28567843 & Low-CpG & 7.41887E-06 & 2.28407E-05 \\
\hline GSTM4 & -97.92513 & 1 & 109998812 & Low-CpG & $9.94493 \mathrm{E}-06$ & $1.62138 \mathrm{E}-05$ \\
\hline CIB4 & -99.87754 & 2 & 26718375 & Low-CpG & 0.000282136 & 3.64575E-07 \\
\hline TMBIM4 & -100.22459 & 12 & 64851491 & Low-CpG & 3.88671E-06 & 2.4432E-05 \\
\hline LOC339535 & -103.632 & 1 & 236716068 & Low-CpG & $5.41422 \mathrm{E}-06$ & 8.0032E-06 \\
\hline SNORD115-38 & -103.94379 & 15 & 23034641 & Low-CpG & 3.08714E-06 & $1.30636 \mathrm{E}-05$ \\
\hline HCCA2 & -105.64957 & 11 & 1601150 & Low-CpG & $1.64093 \mathrm{E}-05$ & $1.65941 \mathrm{E}-06$ \\
\hline PARP4 & -105.90702 & 13 & 23979063 & Low-CpG & $2.30641 \mathrm{E}-05$ & $1.11266 \mathrm{E}-06$ \\
\hline DLGAP2 & -106.78054 & 8 & 1442761 & Low-CpG & $1.34894 \mathrm{E}-06$ & $1.5558 \mathrm{E}-05$ \\
\hline TMEM22 & -108.01178 & 3 & 138039519 & Low-CpG & $8.62848 \mathrm{E}-06$ & $1.83184 \mathrm{E}-06$ \\
\hline TCAM1 & -109.0501 & 17 & 59288076 & Low-CpG & 3.68175E-06 & $3.38015 \mathrm{E}-06$ \\
\hline CEP63 & -111.64598 & 3 & 135690134 & Low-CpG & 0.000347835 & $1.96801 \mathrm{E}-08$ \\
\hline PAK2 & -112.77409 & 3 & 197954174 & Low-CpG & $5.13802 \mathrm{E}-06$ & $1.02753 \mathrm{E}-06$ \\
\hline FAM9A & -112.86534 & $\mathrm{x}$ & 8729344 & Low-CpG & $2.79992 \mathrm{E}-06$ & $1.84638 \mathrm{E}-06$ \\
\hline CCDC83 & -114.29396 & 11 & 85246352 & Low-CpG & $5.92682 \mathrm{E}-06$ & $6.27745 \mathrm{E}-07$ \\
\hline SNORD114-15 & -115.87882 & 14 & 100508183 & Low-CpG & $9.26565 \mathrm{E}-06$ & 2.78767E-07 \\
\hline$C D C A 7 L$ & -120.37022 & 7 & 21930929 & Low-CpG & $2.20559 \mathrm{E}-06$ & $4.16346 \mathrm{E}-07$ \\
\hline WDR27 & -120.65469 & 6 & 169839513 & Low-CpG & $5.12794 \mathrm{E}-06$ & $1.67721 \mathrm{E}-07$ \\
\hline$B E C N 1$ & -124.31615 & 17 & 38230497 & Low-CpG & $6.43061 \mathrm{E}-06$ & $5.75617 \mathrm{E}-08$ \\
\hline AGAP11 & -138.8236 & 10 & 88746560 & Low-CpG & 8.04749E-08 & $1.62922 \mathrm{E}-07$ \\
\hline
\end{tabular}


Table S5 Gene ontology annotation of 60 genes with significantly hypermethylation and hypomethylation of overlap genes between B (pericarcinous tissues) vs. C (pancreatic cancer tissue) and a (blood) vs. B (pericarcinous tissues)

\begin{tabular}{|c|c|c|c|c|c|c|c|c|c|c|c|}
\hline GOID & Ontology & Term & Level & q & $\mathrm{m}$ & $\mathrm{t}$ & $\mathrm{k}$ & Gene IDs & Symbols & Log odds ratio & $\mathrm{P}$ \\
\hline GO: 0000045 & Biological process & $\begin{array}{l}\text { Autophagosome } \\
\text { assembly }\end{array}$ & 4 & 5 & 38 & 45,240 & 127 & C1IDX9, O94817, K7EPZ0, K7EQQ7, Q14457 & ATG12, ATG12, BECN1, BECN1, BECN1 & 5.550627 & $5.82 \mathrm{E}-05$ \\
\hline GO: 0006914 & Biological process & Autophagy & 1 & 12 & 159 & 45,240 & 127 & $\begin{array}{l}\text { C1IDX9, O94817, E7EV84, K7ELY9, K7EMA2, K7EN35, } \\
\text { K7EPZ0, K7EQQ7, K7ER46, K7ERY0, K7ESG3, Q14457 }\end{array}$ & $\begin{array}{l}\text { ATG12, ATG12, BECN1, BECN1, BECN1, BECN1, } \\
\text { BECN1, BECN1, BECN1, BECN1, BECN1, BECN1 }\end{array}$ & 4.748706 & 3.84E-10 \\
\hline GO:1905037 & Biological process & $\begin{array}{l}\text { Autophagosome } \\
\text { organization }\end{array}$ & 2 & 5 & 38 & 45,240 & 127 & C1IDX9, 094817, K7EPZ0, K7EQQ7, Q14457 & ATG12, ATG12, BECN1, BECN1, BECN1 & 5.550627 & $5.82 \mathrm{E}-05$ \\
\hline GO: 0003857 & Molecular function & $\begin{array}{l}\text { 3-hydroxyacyl-CoA } \\
\text { dehydrogenase activity }\end{array}$ & 1 & 4 & 13 & 45,240 & 127 & C9JE81, C9JEY0, C9K0M0, P55084 & HADHB, HADHB, HADHB, HADHB & 6.776187 & $3.76 \mathrm{E}-05$ \\
\hline GO: 0003988 & Molecular function & $\begin{array}{l}\text { Acetyl-CoA } \\
\text { C-acyltransferase } \\
\text { activity }\end{array}$ & 1 & 4 & 10 & 45,240 & 127 & C9JE81, C9JEY0, C9K0M0, P55084 & HADHB, HADHB, HADHB, HADHB & 7.154699 & $1.67 \mathrm{E}-05$ \\
\hline GO: 0004300 & Molecular function & $\begin{array}{l}\text { Enoyl-CoA hydratase } \\
\text { activity }\end{array}$ & 1 & 4 & 8 & 45,240 & 127 & C9JE81, C9JEY0, C9K0M0, P55084 & HADHB, HADHB, HADHB, HADHB & 7.476627 & $6.38 \mathrm{E}-06$ \\
\hline GO: 0016507 & Cellular component & $\begin{array}{l}\text { Mitochondrial fatty } \\
\text { acid beta-oxidation } \\
\text { multienzyme complex }\end{array}$ & 8 & 4 & 5 & 45,240 & 127 & C9JE81, C9JEY0, C9K0M0, P55084 & HADHB, HADHB, HADHB, HADHB & 8.154699 & $6.42 \mathrm{E}-07$ \\
\hline GO: 0036125 & Cellular component & $\begin{array}{l}\text { Fatty acid beta- } \\
\text { oxidation multienzyme } \\
\text { complex }\end{array}$ & 1 & 4 & 5 & 45,240 & 127 & C9JE81, C9JEY0, C9K0M0, P55084 & HADHB, HADHB, HADHB, HADHB & 8.154699 & $6.42 \mathrm{E}-07$ \\
\hline GO: 0016508 & Molecular function & $\begin{array}{l}\text { Long-chain-enoyl-CoA } \\
\text { hydratase activity }\end{array}$ & 1 & 4 & 6 & 45,240 & 127 & C9JE81, C9JEY0, C9K0M0, P55084 & HADHB, HADHB, HADHB, HADHB & 7.891664 & $1.6 \mathrm{E}-06$ \\
\hline GO: 0016509 & Molecular function & $\begin{array}{l}\text { Long-chain-3- } \\
\text { hydroxyacyl-CoA } \\
\text { dehydrogenase activity }\end{array}$ & 1 & 4 & 5 & 45,240 & 127 & C9JE81, C9JEY0, С9K0M0, P55084 & HADHB, HADHB, HADHB, HADHB & 8.154699 & $6.42 \mathrm{E}-07$ \\
\hline GO: 0005960 & Cellular component & $\begin{array}{l}\text { Glycine cleavage } \\
\text { complex }\end{array}$ & 5 & 4 & 5 & 45,240 & 127 & H3BNV1, H3BQ30, H3BUG8, P23434 & GCSH, GCSH, GCSH, GCSH & 8.154699 & $6.42 \mathrm{E}-07$ \\
\hline
\end{tabular}

Statistical test method: hypergeometric test/Fisher's exact test. FDR correction method: Benjamini and Hochberg. 


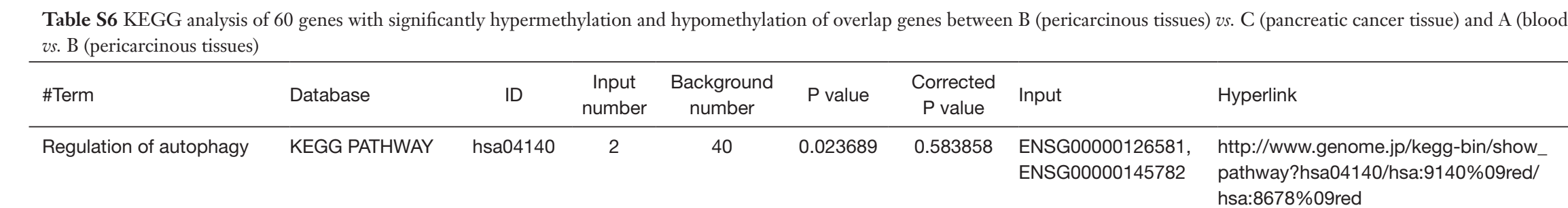

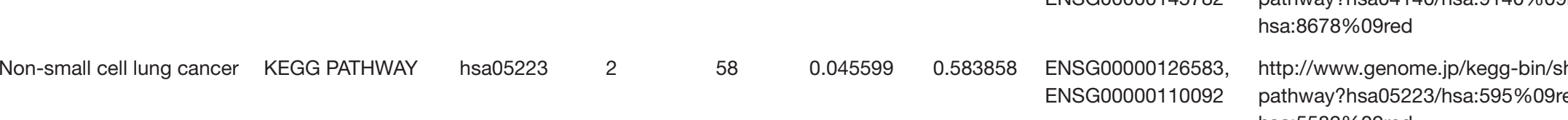

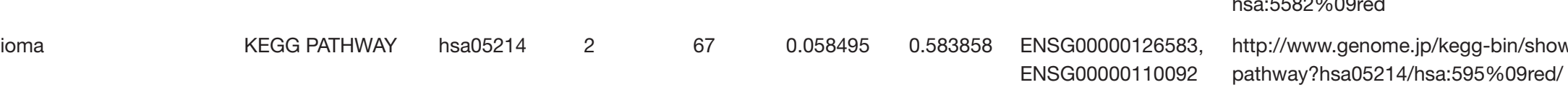

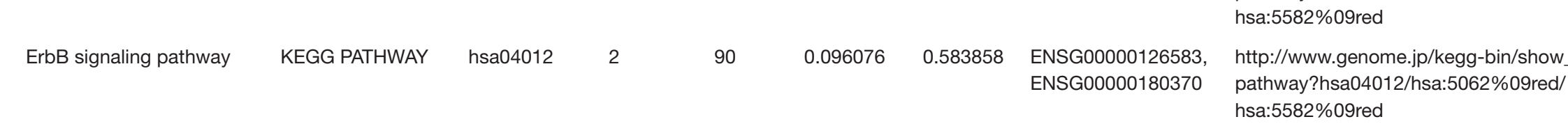

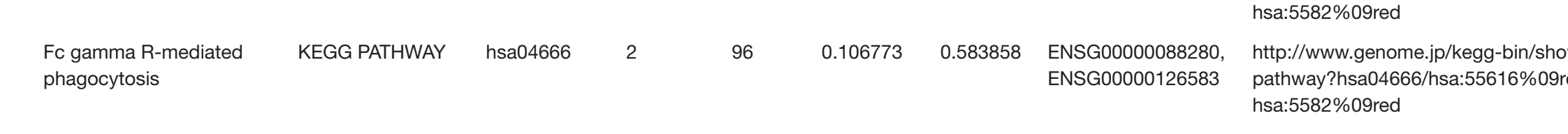

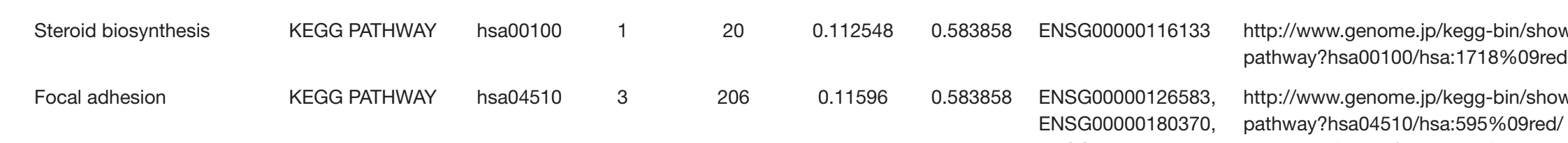

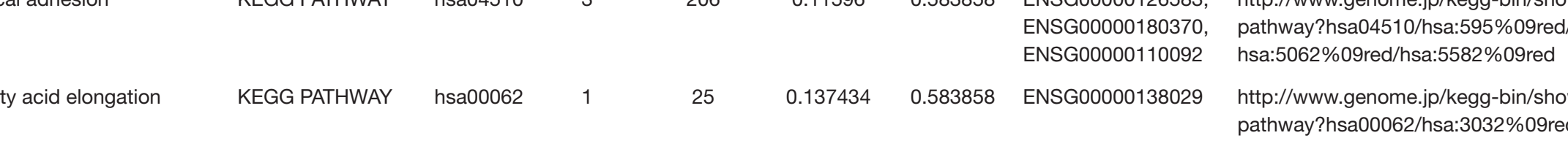

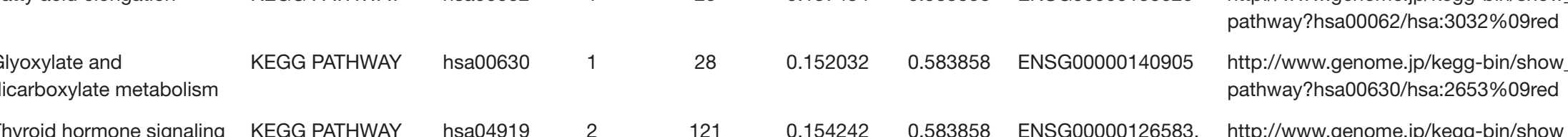

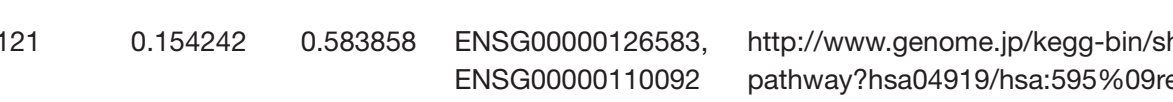

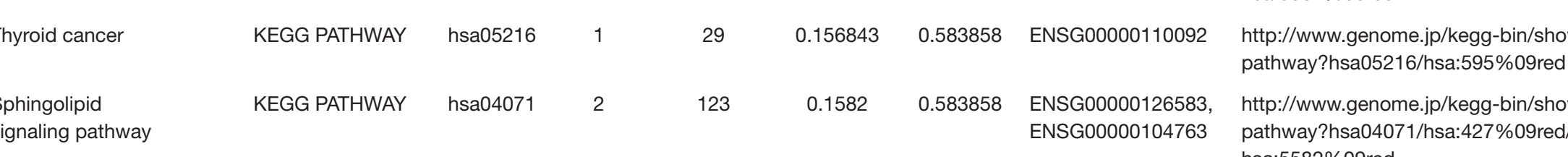

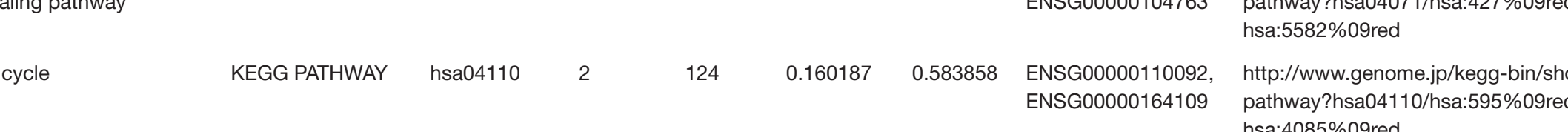

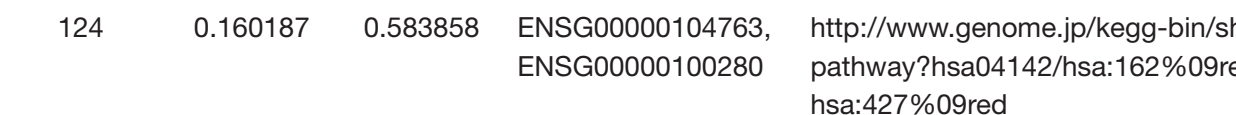

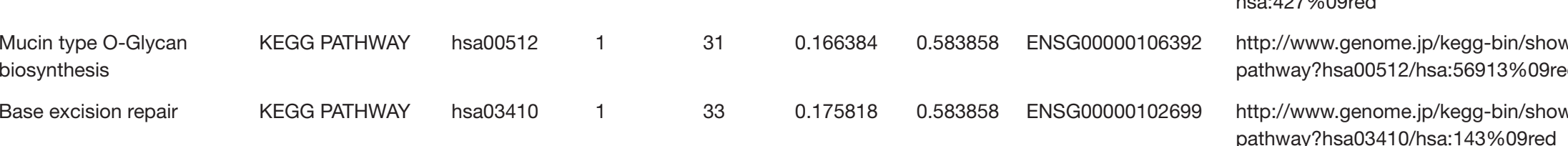

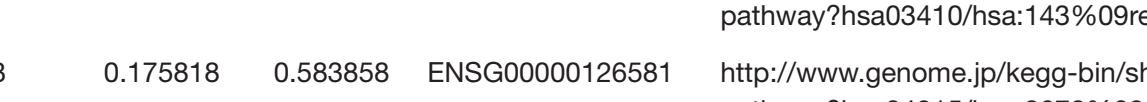

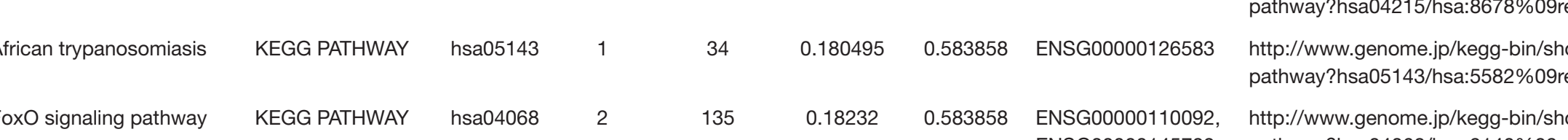
Mecosers

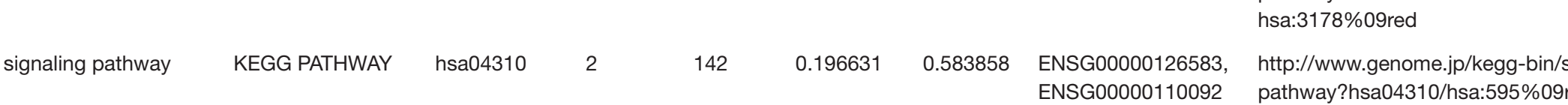

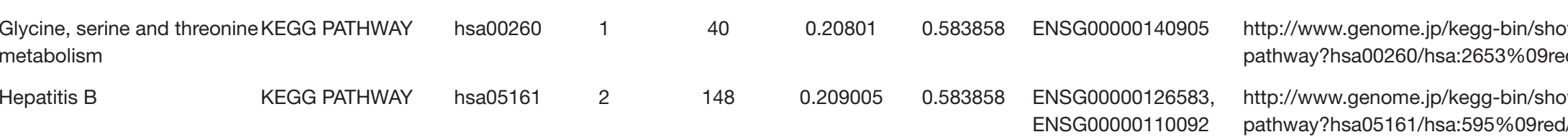

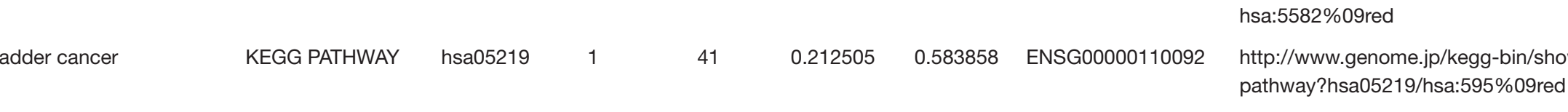

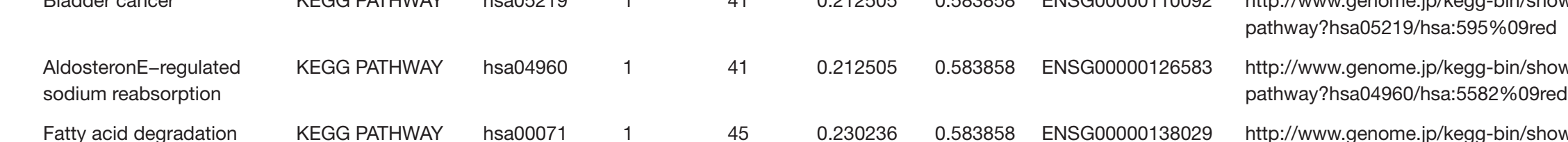

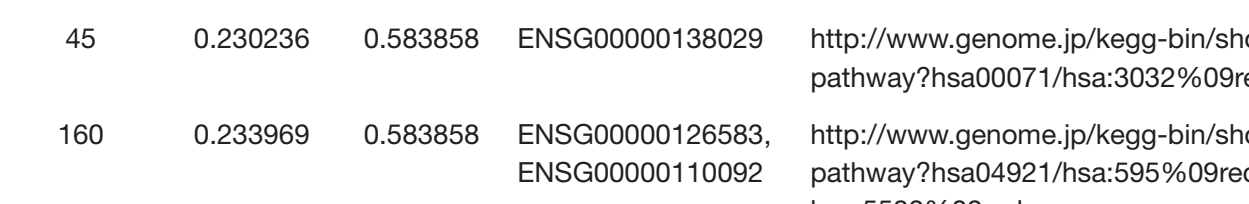

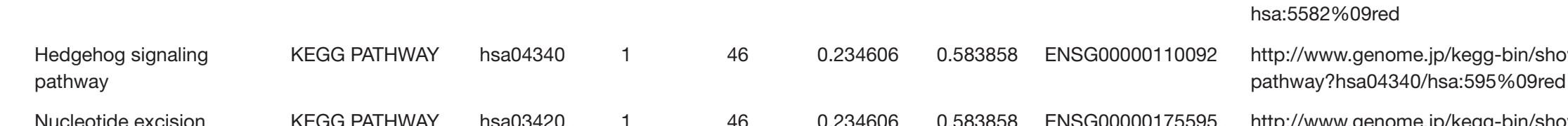

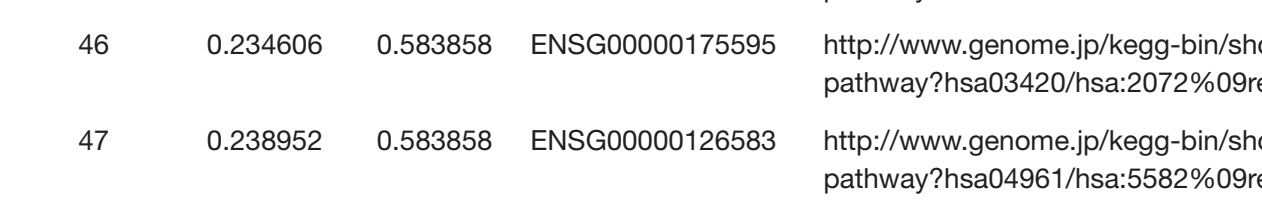

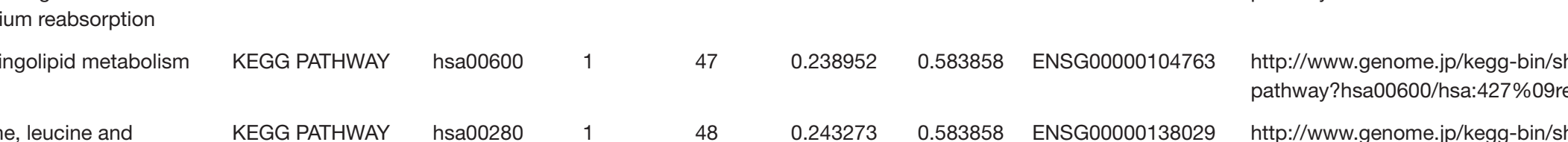

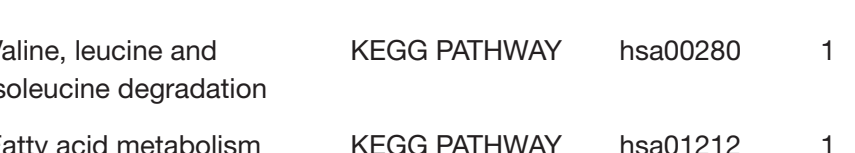

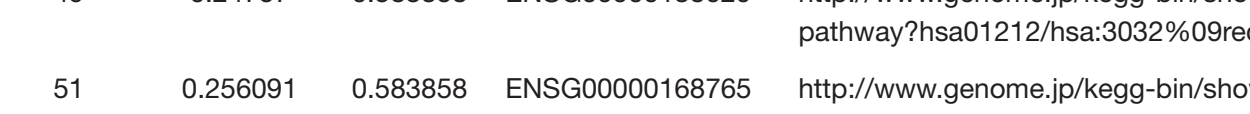

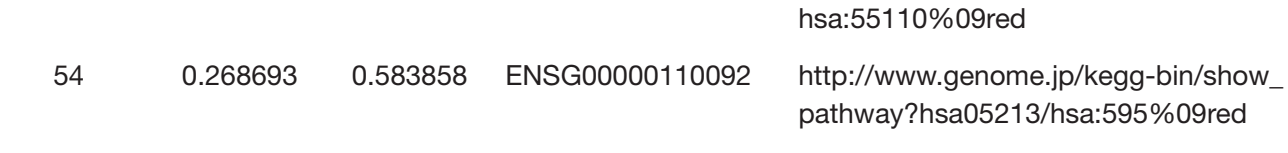

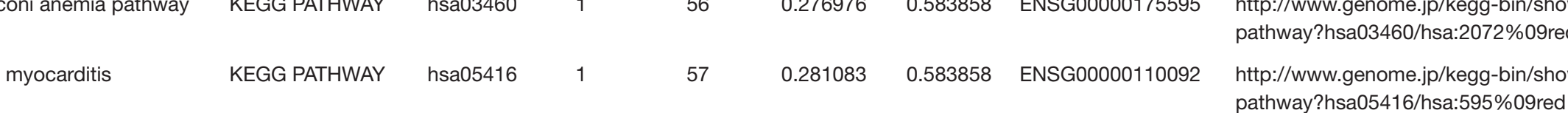

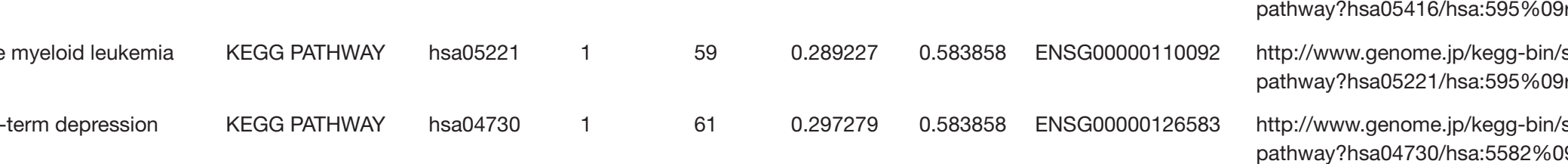

